Canadian

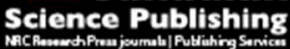

Canadian Geotechnical Journal

Revue canadienne de géotechnique

\title{
ULTIMATE LIMIT STATE RELIABILITY-BASED DESIGN OF AUGERED CAST-IN-PLACE PILES CONSIDERING LOWER- BOUND CAPACITIES
}

\begin{tabular}{|r|l|}
\hline Journal: & Canadian Geotechnical Journal \\
\hline Manuscript ID & cgj-2016-0145.R1 \\
\hline Danuscript Type: & Article \\
\hline Complete List of Authors: & $\begin{array}{l}\text { Reddy, Seth; GRI, Inc. } \\
\text { Stuedlein, Armin; Oregon State University, School of Civil and Construction } \\
\text { Engineering }\end{array}$ \\
\hline Keyword: & $\begin{array}{l}\text { ACIP piles; Ultimate limit state; Reliability; Statistics; Resistance factors; } \\
\text { Lower bound limits }\end{array}$ \\
\hline \multicolumn{2}{|c}{} \\
\hline
\end{tabular}




\title{
ULTIMATE LIMIT STATE RELIABILITY-BASED DESIGN OF AUGERED CAST-IN- PLACE PILES CONSIDERING LOWER-BOUND CAPACITIES
}

\author{
Seth C. Reddy ${ }^{1}$, Ph.D., E.I., and Armin W. Stuedlein ${ }^{2}$, Ph.D., P.E.
}

${ }^{1}$ Staff Engineer, Geotechnical Resources, Inc. (GRI), 9750 SW Nimbus Avenue, Beaverton, OR, 97008, sreddy@gri.com

${ }^{2}$ Associate Professor, School of Civil and Construction Engineering, Oregon State University, 101 Kearney Hall, Corvallis, OR, 97331. (541) 737-3111 armin.stuedlein@oregonstate.edu (Corresponding Author) 


\section{ABSTRACT}

The use of augered cast-in-place (ACIP) piles for transportation infrastructure requires an appropriate reliability-based design (RBD) procedure. In an effort to improve the accuracy of an existing design model and calibrate appropriate resistance factors, this study presents a significantly revised RBD methodology for estimating the shaft and toe bearing capacity of ACIP piles using a large database consisting of static loading tests in predominately granular soils. The proposed design models are unbiased, as opposed to those currently recommended. Based on the reasonable assumption that a finite lower-bound resistance limit exists, lower-bound design lines were developed for shaft and toe bearing resistance by applying a constant ratio to the proposed design models. Resistance factors are calibrated at the strength or ultimate limit state (ULS) for ACIP piles loaded in compression and tension for two commonly used target probabilities of failure with and without lower bound limits. For piles loaded in compression, separate resistance factors are calibrated for the proposed shaft and toe bearing resistance models. The inclusion of a lower-bound limit for piles loaded in tension resulted in a 24 to 50 percent increase in the calibrated resistance factor. For piles loaded in compression, the application of a lower-bound limit resulted in a 20 to 150 percent increase in the calibrated resistance factor, and represents a significant increase in useable pile capacity. Although the impact of a lower bound limit on resistance factor calibration is directly dependent on the degree of uncertainty in the distribution of resistance, this effect is outweighed by the type of distribution selected (i.e. normal, lognormal) at more stringent target probabilities of failure due to differences in distribution shape at the location of the lower bound limit. A companion paper explores the use of the revised ULS in a reliability-based serviceability limit state (SLS) design framework.

Author Keywords: ACIP piles; Ultimate limit state; Reliability; Statistics; Resistance factors; Lower bound limits. 


\section{INTRODUCTION}

Subjective global factors of safety, defined as the ratio of resistance and load, have traditionally been used to account for variations in the predicted resistance and loads to provide satisfactory system performance over a given design life. Yet, the actual margin of safety, defined as the difference between the resistance and load, can vary significantly for the same factor of safety due to differences in their respective uncertainties (Kulhawy and Phoon 2006). Many of the problems associated with traditional deterministic design procedures can be resolved by identifying, mathematically characterizing, and treating the various sources of uncertainty; this general concept forms the basis for RBD. Fortunately, there is an increasing awareness among the geotechnical community regarding the evaluation and treatment of uncertainties associated with soil properties and design models. Despite the growing popularity of auger cast-in-place piles due to their flexibility, speed, and ease of installation (Neely 1991; McVay et al. 1994; O’Neill 1994; Vipulanandan 2007), many of the currently recommended design methods for ACIP piles are set in a deterministic framework (e.g. allowable stress design or ASD).

Auger cast-in-place (ACIP) piles are constructed by advancing a continuous flight auger into the ground. Upon reaching the desired depth, high-strength grout or concrete is pumped through the hollow stem under controlled pressures as the auger is slowly withdrawn to produce a continuous grouted column. Since the sidewalls of the borehole are supported by the soil-filled augers, a slurry or temporary casing is not necessary for maintaining stability. Steel reinforcements may then be inserted through the fluid grout to provide tensile capacity and flexural rigidity. The reader is referred to Neely (1991) and Brown et al. (2007) for additional construction details. 
The construction techniques used to install bored piles influence load-transfer (Neely 1991, O’Neill 1994, Prezzi and Basu 2005). Because ACIP piles are constructed differently than conventional drilled shafts, an ACIP pile-specific design methodology is necessary to accurately estimate pile capacity. To date, most methodologies used to estimate the capacity of ACIP piles have been modified from driven displacement pile and drilled shaft design methods (e.g. Meyerhof 1976; O’Neill and Reese 1999; Brown et al. 2007). Additional studies (e.g. van den Elzen 1979; O’Dell and Pool 1979; Park et al. 2012) have suggested techniques for the design of ACIP piles based on correlations with in situ tests; however, most have been developed using a limited amount of static loading test data. Recently, Stuedlein et al. (2012) formulated design equations for shaft and toe bearing resistance using loading tests on instrumented piles and a previously reported database of ACIP piles. Stuedlein and Reddy (2013) highlighted some potential shortcomings associated with modeling for RBD of ACIP piles.

Although the RBD methodology described by Stuedlein et al. (2012) provided a first step toward an ultimate limit state (ULS) load and resistance factor design (LRFD) procedure for ACIP piles, several critical factors controlling the factored resistance could be improved. For example, the number of piles used to generate the shaft and toe bearing resistance model was relatively small, equal to 56 and 31 , respectively. Numerous proof loading tests and instrumented loading tests and have been reported or identified since then, allowing for a necessary re-assessment of the models. In addition, the resistance factors calibrated in Stuedlein et al. (2012) considered the entire distribution of pile capacity, whereas the consideration of realistic lower-bound capacities should be incorporated into RBD calibrations owing to their potential significance on the resulting factored resistance (Najjar and Gilbert 2009). 
In this study, a new database of static pile loading tests performed on ACIP piles installed in predominately granular soils is analyzed to develop revised and unbiased design equations for unit shaft and toe bearing resistance. These models are statistically characterized and compared to existing design equations for ACIP piles. Resistance factors are calibrated for ACIP piles loaded in compression and tension using accepted load statistics. For compressive loads, separate resistance factors are calibrated for use with shaft and toe bearing resistance models. Lower-bound limits for the unit shaft and toe bearing resistance models are imposed on the resulting source distributions in order to improve the estimate of the calibrated resistance factors. Comparisons are made between resistance factors calibrated with lower-bound limits and those using the conventional calibration approach. The effect of variability of the lower-bound limit on the resistance factor calibration was also investigated. This paper illustrates the benefits of incorporating lower-bound limits on capacity for ultimate limit state RBD of ACIP piles in granular soils. In a companion paper (Reddy and Stuedlein 2016), the use of the ULS model developed herein is applied to the calibration of a reliability-based serviceability limit state design procedure.

\section{PILE LOAD TEST DATABASE}

In an effort to satisfactorily capture the variability in granular soil deposits, pile materials and geometry, and typical fabrication and construction procedures, a database of full-scale pile loading tests was compiled and may represent the largest database of its kind. The database consisted of 112 static loading tests performed on ACIP piles installed in predominately granular soils (presented Appendix Table A1) was developed from 51 loading tests compiled by Neely (1991), 25 compiled by McCarthy (2008), 12 contributed by members of the Deep Foundations Institute (DFI) ACIP Pile Committee (Personal Communication 2013), ten presented in local 
ASCE Chapter meetings and described by Stuedlein et al. (2012), ten compiled by Park et al. (2010), three from load tests conducted by Mandolini et al. (2002), and one from O’Neill et al. (1999). Although the loading procedures varied based on regional practice, the majority of load tests were performed in accordance with ASTM D1143. The diameter, $B$, and embedment depth ranged from 300 to $800 \mathrm{~mm}$ and 4.5 to $29 \mathrm{~m}$, respectively. None of the piles from Neely (1991) or McCarthy (2008) were instrumented, whereas all the piles in Park et al. (2010), Mandolini (2002), and O'Neill et al. (1999), and seven of the piles from DFI and four of the piles from Stuedlein et al. (2012) were instrumented with strain gauges. Some of the piles were loaded in two or more cycles; in these cases, an equivalent monotonically increasing load-displacement curve was analyzed for capacity, as described below. The majority of the ACIP piles used to develop the database herein were tested in compression. However, five piles obtained from Neely (1991) were tested in tension, but indicated no appreciable difference in unit shaft resistance from those piles tested in compression.

Sources of subsurface information included boring logs, standard penetration test (SPT) blow counts, $N_{S P T}$, and cone penetrometer test (CPT) records. These data were used to estimate the density of the relevant soil units, and, along with ground water elevations, the vertical effective stresses. The piles were installed in deposits of loose to very dense sands, silty sand, sandy silt, clayey sand, and gravelly sand. The observed load transfer for instrumented piles that were embedded in plastic silt and clay or peat layers were not included herein. Piles that were installed to bear on weakly cemented limestone or partially cemented silts were excluded in the development of the unit toe bearing resistance model. Therefore, the application of the design procedures described in the subsequent sections of this paper are limited to cohesionless soils. 


\section{DEVELOPMENT OF THE ULTIMATE PILE RESISTANCE}

There are numerous methods for interpreting the capacity of a pile from the loaddisplacement curves resulting from static loading tests. In this study, and except for those instrumented tests presented in Stuedlein et al. (2012), the stability plot method (Chin and Vail 1973, Neely 1991), which assumes the load-displacement, $Q-\delta$, relationship follows a hyperbolic curve, was used to calculate the measured ultimate total resistance:

$$
Q=\frac{\delta}{m \cdot \delta+C}
$$

where $Q=$ the load applied to the pile head, $\delta=$ the pile head displacement, $m=$ the coefficient describing the slope of the $\delta / Q-\delta$ curve, and $C=$ the intercept of the $\delta / Q-\delta$ curve. The measured ultimate total resistance, $R_{T, m}$, was determined by calculating $Q$ when $\delta=10$ percent of the pile diameter and this required limited extrapolation of some $Q-\delta$ curves.

The measured ultimate shaft resistance, $R_{s, m}$, equal to the inverse of the initial slope of the $\delta / Q-\delta$ curve, was determined using the stability plot method since toe bearing resistance is often negligible at small displacements (Chin and Vail 1973; Hirany and Kulhawy 1988, Neely 1991). The measured ultimate toe bearing resistance, $R_{t, m}$, was assumed to be equal to the difference between $R_{T, m}$ and $R_{s, m}$ at $\delta / B=10$ percent. The reader is referred to Chin and Vail (1973) or Neely (1991) for additional background information. Stuedlein et al. (2012) described the development of shaft, toe bearing, and ultimate resistances for six non-instrumented and four instrumented ACIP piles, the latter of which was determined from the observed load-transfer curves after correcting for residual load effects and stress-dependent concrete modulus, and agreed with those capacities determined using the stability plot method. 


\section{REVISED DESIGN EQUATIONS}

\section{Ultimate Shaft Resistance for Auger Cast-in-Place Piles}

Effective stress governs shearing resistance along the shaft of a pile, hence, the dimensionless $\beta$-coefficient, equal to the unit shaft resistance, $r_{s}$, normalized by vertical effective stress, $\sigma_{v}^{\prime}$, is frequently used for the estimation of shaft resistance of drilled foundations. Although the $\beta$-coefficient may be expressed as $\beta=K \tan (\delta)$, where $K=$ the lateral effective stress coefficient and $\delta=$ the interface friction angle (Kulhawy 2004), the $\beta$-coefficient is typically correlated with depth, and occasionally a proxy for relative density, owing to the difficulties associated with evaluating post-installation values of $K$ and $\delta$. For example, Brown et al. (2007) recommended the Federal Highway Administration (FHWA) approach (O'Neill and Reese 1999) which correlates depth and $N_{S P T}$ to determine the $\beta$-coefficient for ACIP piles. This methodology assumes that the construction process for ACIP piles is similar to that of drilled shafts. In reality, the stress changes which take place in the surrounding soil during installation and the concrete grout delivery method are different for drilled shafts and ACIP piles and should lead to differences in load transfer. Due to the differences in construction between ACIP piles and other drilled foundations, the use of a pile-specific design methodology is preferred.

Based on a limited number of $\beta$-coefficients $(n=65)$ back-calculated from instrumented and non-instrumented loading tests, Stuedlein et al. $(2012,2013)$ provided an initial ACIP pilespecific RBD model for predicting shaft resistance, where the $\beta$-coefficient is estimated as a function of pile length. A revised shaft resistance model based on 143 back-calculated $\beta$ coefficients from 93 piles in the new database (Table A1) is proposed herein. $\beta$-coefficients were back-calculated from instrumented piles using unit shaft resistances measured from loadtransfer curves and the average effective stress for the granular layers only. For non- 
instrumented piles in predominately granular soils, $\beta$-coefficients were obtained using the average unit shaft resistance calculated from the stability plot method and pile geometry, and the average vertical effective stress along the length of the pile, providing an average $\beta$-coefficient at the mid-point of the shaft. In this study, back-calculated $\beta$-coefficients less than 0.17 were rejected based on the consideration of a realistic minimum friction angle for loose sand, $\phi^{\prime}=26$ degrees, poor construction techniques that result in a lower-bound coefficient of active earth pressure, $K_{a}=0.35$ (NAVFAC 1986), and the assumption of $\delta / \phi^{\prime}=1$ for rough concreted piles (Kulhawy 1991). Some non-instrumented piles exhibited poor $Q-\delta$ responses (e.g., from McCarthy 2008) and were excluded because a reliable estimate of shaft resistance could not be made. The revised $\beta$-coefficient model with depth, $z$, is shown in Fig. 1 and is given by:

$$
\begin{array}{ll}
\beta=2.25 & \text { for } z \leq 3.20 \mathrm{~m} \\
\beta=\frac{1}{22,222} \cdot z^{\left(\frac{29.1}{z}\right)}+0.48 \text { for } z>3.20 \mathrm{~m}
\end{array}
$$

The proposed shaft resistance model is characterized with a mean bias, $\lambda_{\mu, s}$, (the ratio of measured to predicted $\beta$-coefficient), equal to 1.00 , and a coefficient of variation, $C O V_{s}$, defined as the ratio of the standard deviation and the mean bias, equal to 51.3 percent, slightly larger than that reported by Stuedlein et al. (2012) due to the addition of data from a broader dataset. For comparison purposes, the FHWA method recommended by Brown et al. (2007) for ACIP piles and $N_{S P T}>15$ blows per foot is illustrated in Figure 1. Evaluation of the FHWA model using the database compiled herein, and using measured $N_{S P T}$ yielded $\lambda_{\mu, s}=1.00$ with a $C O V_{s}=59.8$ percent. Equation (2) is similar to that proposed by Coleman and Arcement (2002) for ACIP piles installed in silty and sandy soils. Because the majority of the piles used in the current 
dataset are installed in purely granular deposits, the use of Eqn. (2) is preferred for these conditions.

An appropriate design model will provide a consistent level of accuracy over the entire range of resistances considered; in other words, the sample biases must be independent of the magnitude of the nominal resistance (Bathurst et al. 2008; Stuedlein et al. 2012). Stuedlein et al. (2012) found that the FHWA model was unbiased at a significance level, $\alpha$, equal to 0.05 . However, using the new database, it was determined that the FHWA model does depend on the magnitude of nominal (predicted) $\beta$-coefficient. The Spearman rank correlation test for the FHWA model yielded a correlation coefficient, $\rho_{s}=0.44$ and a corresponding two-tail $p$-value $=$ $5.5 \mathrm{E}^{-8}$, indicating convincing evidence for correlation at $\alpha=0.05$. Based on a $\rho_{s}=0.14$ and a two-tail $p$-value $=0.10$, the accuracy of the proposed unit shaft resistance model (Eqn. 2$)$ was determined to be independent of magnitude and is therefore unbiased. Figure 2a illustrates the relationship between point bias and nominal $\beta$-coefficient for the FHWA model and the model proposed in this study. Based on the data reported by Neely (1991) incorporated herein and the general understanding of the field response of drilled foundations (Fellenius 2002), the proposed model is assumed to be valid for estimating shaft resistance of ACIP piles loaded in compression and tension (Stuedlein et al. 2012).

\section{Ultimate Toe Bearing Resistance for Auger Cast-in-Place Piles}

Several methods have been proposed to estimate the ultimate toe bearing resistance, $R_{t}$, of drilled foundations based on correlations with the SPT (e.g. Meyerhof 1976; Wright and Reese 1979; Brown et al. 2007; Stuedlein et al. 2012) and the CPT (e.g. Douglas 1983; Park et al. 2010). Brown et al. (2007) suggested that one-half of the magnitude for the Meyerhof (1976) SPT-based unit toe bearing resistance model for driven piles would be appropriate for the design 
of ACIP piles. However, the loading test data reported by Neely (1991) suggested that the ultimate unit toe bearing resistance, $r_{t}$, of ACIP piles was consistently larger than that for drilled shafts over a wide range in $N_{S P T}$. The tendency for larger toe bearing resistance in ACIP piles was confirmed by instrumented loading test data provided by Stuedlein et al. (2012).

The relative displacements, $\delta / B$, for the piles used to develop the proposed model ranged from 2.1 to 12.2 percent (Fig. 3), and were deemed appropriate for satisfying typical ULS requirements despite the relatively low toe displacements observed for some of the pile case histories. In general, unit toe bearing resistance should be larger for piles installed in denser soils, and it should steadily increase as the pile is displaced further into the ground during loading. However, the empirical plateau observed in Figure 3 may be due to unloading and/or loosening of the soil at the base of the cavity during augering (Neely 1991; Stuedlein et al. 2012). In other words, the $N_{S P T}$ observed prior to pile installation may not be representative of the post-installation conditions directly beneath the pile toe. Further research into the phenomenological response of the soil to augering is encouraged.

Forty-two pile loading tests, including those compiled by Neely (1991), Park et al. (2010), Stuedlein et al. (2012), and the DFI (2013), shown in Table A1, provide the basis for an ultimate unit toe resistance model revised from Stuedlein et al. (2012). Ultimate unit toe bearing resistance was obtained by dividing $R_{t, m}$ by the nominal pile toe area. In an effort to reduce the uncertainty associated with the proposed $r_{t}$ model, the energy and overburden stress-corrected blow count, $N_{1,60}$, was computed for each pile and used to generate the revised ultimate unit toe bearing resistance model:

$$
r_{t}=0.22 \cdot N_{1,60} \leq 4.84 \mathrm{MPa}
$$


where $N_{1,60}$ is averaged $1 B$ above and $2 B$ below the pile toe. Figure 3 shows the proposed design model along with the $r_{t}$ model proposed by Brown et al. (2007) for comparison (n.b., this model uses $N_{60}$ ). In consideration of the new toe bearing resistance data, the upper limit is slightly smaller than that suggested by Stuedlein et al. (2012) and the initial rate of $r_{t}$ with $N_{1,60}$ increased, due in part to the new data as well as the use of $N_{1,60}$ instead of $N_{60}$. The proposed toe bearing resistance model is statistically characterized with $\lambda_{\mu, t}=1.01$ and $C O V_{t}=27.8$ percent, and is unbiased as determined using the Spearman rank correlation test $\left(\rho_{s}=-0.08\right.$; $p$-value $=$ 0.62). On the other hand, the FHWA method was found to be inaccurate with $\lambda_{\mu, t}=2.43$, more uncertain with a $C O V_{t}=43.6$ percent, and significantly biased with respect to nominal resistance $\left(\rho_{s}=-0.70 ; p\right.$-value $\left.=2.8 \mathrm{E}^{-7}\right)$. Figure $2 \mathrm{~b}$ illustrates the relationship between point bias and nominal unit toe bearing resistance for the FHWA model and the model proposed in this study. The revised ACIP pile-specific $r_{t}$ model is used for RBD calibrations described below.

\section{RESISTANCE FACTOR CALIBRATION}

The adoption of LRFD in American Association of State Highway and Transportation Officials (AASHTO) design specifications $(2007,2012)$ and the recently imposed reliabilitybased design requirements by the FHWA (2007) have led numerous researchers to develop resistance factors for foundations including drilled shafts (e.g., Phoon et al. 2003; Basu and Salgado 2012, Ching et al. 2013) and driven piles (Paikowsky et al. 2004; Allen 2005, 2007; Reddy and Stuedlein 2013) among others. This study followed the basic procedure outlined in Allen et al. (2005) and modified by Stuedlein et al. (2012) for multiple loading scenarios where a Monte Carlo simulation (MCS) approach is used to calibrate resistance factors at the ULS (i.e. the strength limit state) for ACIP piles loaded in compression and tension using AASHTO loading statistics and the proposed revised unit toe bearing and shaft resistance models. For piles 
loaded in compression, separate resistance factors are calibrated for use with the proposed shaft and toe bearing resistance models. Lower-bound unit toe bearing and shaft resistances are proposed and incorporated into resistance factor calibration efforts. In order to accelerate the adoption of geotechnical design codes, resistance factors are typically calibrated using load statistics and factors obtained directly from existing structural design codes (e.g. AASHTO 2007). In accordance with AASHTO, the basic limit state design function is expressed as:

$$
\phi_{R} \cdot R_{n, i} \geq \sum_{j=1}^{k} \gamma_{Q, j} \cdot Q_{n, i, j}
$$

where, $Q_{n, i, j}$ and $R_{n, i}$ are the nominal loads and resistance, and $\gamma_{Q, j}$ and $\phi_{R}$ are the load and resistance factors, respectively. The subscripts $i$ and $j$ are used to represent multiple load and resistance sources.

For calibration purposes, the statistics (i.e. mean, COV, type of distribution) associated with the random variables in Eqn. 4 can be characterized in terms of the bias (Allen et al. 2005; Bathurst et al. 2008). By using the distributions of bias, the uncertainty associated with each random variable in Eqn. (4) is explicitly incorporated into the resistance factors. Resistance model bias, $\lambda_{R}$, defined as the ratio of observed resistance and the resistance predicted using the proposed revised design models, accounts for the variation present in the model input parameters (e.g. $\sigma^{\prime}{ }_{v}, N_{1,60}$ ), the uncertainty associated with the selection of failure criterion and prediction model, the random and spatial variation of the soil and pile properties, variations in local construction practices, the quality of the data, and the degree of consistency used to interpret the available data when obtained from multiple sources (Allen et al. 2005; Stuedlein et al. 2012). For calibration purposes, the limit state equation may be expressed in terms of the margin of safety, $g_{i}$, and the load and resistance biases as (Bathurst et al. 2011): 


$$
g_{i}=\lambda_{R, i} \frac{\gamma_{\text {avg }}}{\phi_{R}}-\lambda_{Q, i} \geq 0
$$

where, $g_{i}$ is the distribution of the margin of safety, $\gamma_{\text {avg }}$ is a weighted load factor representing multiple load sources, and $\lambda_{Q}$ is the bias of the applied load. In the case of multiple load sources, as is common for bridges and other superstructures, $\lambda_{Q}$, can be expressed as (Stuedlein et al. 2012):

$$
\lambda_{Q}=\frac{\lambda_{Q, D} \cdot \eta+\lambda_{Q, L}}{\eta+1}
$$

where $\lambda_{Q, D}$, and $\lambda_{Q, L}$ are the bias in dead and live loads, respectively, and $\eta$ is the ratio of dead to live load, which ranges from 2 to 5 for most highway bridges (Allen 2005). In the case of multiple loads, weighted load factor, $\gamma_{a v g}$, can be used (Stuedlein et al. 2012):

$$
\gamma_{\text {avg }}=\frac{\lambda_{Q, D} \cdot \gamma_{Q, D} \cdot \eta+\lambda_{Q, L} \cdot \gamma_{Q, L}}{\lambda_{Q, D} \cdot \eta+\lambda_{Q, L}}
$$

where $\gamma_{Q, D}$ and $\gamma_{Q, L}$ equal the dead and live load factors. Because this study focused on calibrating resistance factors for the AASHTO Strength Limit I state, load statistics were obtained directly from Nowak (1999) and Section 3.4.1 of AASHTO (2012) and therefore $\lambda_{Q, D}=$ $1.05, \lambda_{Q, L}=1.15, \gamma_{Q, D}=1.25$, and $\gamma_{Q, L}=1.75$; live and dead loads were both assumed to be normally distributed in accordance with Nowak (1999). The variability associated with dead and live load, $C O V_{Q, D}$ and $C O V_{Q, L}$, was assumed to be 10 and 20 percent, respectively, in accordance with Nowak (1999).

The probability of exceeding the limit state (i.e. failure) is computed as the portion of the distribution of the margin of safety where $g<0$. Resistance factors were computed using the actual $p_{f}$; however, it is occasionally convenient to discuss reliability in terms of an index. 
Assuming the margin of safety is normally distributed, the inverse standard normal function, $\Phi^{-1}$, may be used to map the probability of failure, $p_{f}$, to the reliability index, $\beta$ :

$$
\beta=\Phi^{-1}\left(1-p_{f}\right)
$$

defined as the number of standard deviations between the mean margin of safety and zero. Resistance factors are frequently calibrated using a target or "acceptable" $p_{f}$, which is selected based on the degree of redundancy anticipated in a foundation system (Allen 2005; AASHTO 2012; Stuedlein et al. 2012). In this study, resistance factors were calibrated to target probabilities of failure, equal to 1.0 percent and 0.1 percent based on recommendations by Paikowsky et al. (2004) for redundant and non-redundant piles, respectively. Target probabilities of failure were transformed into reliability indices using Eqn. (8) for ease of comparison to other RBD methodologies.

\section{Determination of Bias Distributions}

In this study, resistance factors are calibrated for ACIP piles loaded axially in tension and compression, with separate distributions for shaft and toe bearing resistance biases, $\lambda_{s}$ and $\lambda_{t}$. For piles loaded in tension, the bias statistics used to calibrate resistance factors are provided by the shaft resistance model for computing the $\beta$-coefficient. For piles loaded in compression, shaft and toe bearing resistance factors were calibrated using the bias statistics provided by the shaft and toe bearing resistance models, respectively. Considering the process in which compressive loads are transferred from the pile to the soil, shaft resistance is mobilized prior to toe bearing resistance, and at smaller relative displacements. By calibrating separate resistance factors for shaft and toe bearing resistance for collective use, this approach assumes the pile has undergone sufficient displacement to mobilize both resistance mechanisms, with no decrease in shearing resistance along the shaft following full strength mobilization. The mean shaft resistance bias, 
$\lambda_{\mu, s}$, and the associated variability, $C O V_{s}$, associated with piles loaded in tension were equal to 1.00 and 51.3 percent, respectively. The same statistics were used to calibrate resistance factors associated with the proposed shaft resistance model for piles loaded in compression. The mean toe bearing resistance bias, $\lambda_{\mu, t}$, and the associated variability, $C O V_{t}$, associated with piles loaded in compression were equal to 1.01 and 27.8 percent, respectively. These shaft and toe bearing resistance bias statistics excludes those values that were rejected on the basis of the proposed lower-bound resistance limits. In order to produce unbiased resistance factors, the resistance bias and associated nominal resistance must be independent. As discussed previously, $\lambda_{s}$ and $\lambda_{t}$ are independent of the nominal unit shaft and toe bearing resistance, $r_{s}$ and $r_{t}$, respectively (Figure $2 \mathrm{a}$ and $b$ ). Figures $4 a$ and $4 b$ presents fitted normal and lognormal distributions with the cumulative distribution function (CDF) of the sample resistance biases, $\lambda_{s}$ and $\lambda_{t}$, respectively. The distribution of shaft and toe bearing resistance bias are best described by a lognormal and normal distribution, respectively.

\section{Incorporation of a Lower-bound Capacity for Reliability Calibrations}

In order to develop an accurate and effective RBD procedure, it is necessary to make a realistic assessment of the probability of failure. However, many in the profession have resisted attempts to use LRFD-based codes due to differences between their experience and design estimates resulting from initial calibrations. Such doubt is not uncommon: Simpson et al. (1981) questioned the ability of traditional reliability assessment methods to accurately determine risk. Horsnell and Toolan (1996), Aggarwal et al. (1996), and Bea et al. (1999) investigated the reliability of piles installed in offshore environments, and found that the calculated probabilities of failure were frequently and considerably greater than the actual rates of failure. 
Although many design models are inherently conservative, the difference between the estimated and observed rates of failure may also be due to the way in which the tails of the load and resistance distributions are modeled (Najjar and Gilbert 2009). Najjar and Gilbert (2009) observed that a resistance distribution truncated by a lower-bound capacity can produce a significant increase in the estimated reliability of a system. This effect was shown to be more pronounced if the uncertainty in the resistance distribution (i.e. COV) is large (Najjar 2005). Najjar (2005) illustrated the effect of a lower-bound capacity on estimated reliability using driven steel pipe piles installed in plastic fine-grained and cohesionless soils by considering the residual shear strength, which can be approximated using the undrained remolded shear strength or the drained residual interface friction angle. Using 34 piles installed in clays, Najjar (2005) found that the ratio of lower-bound capacity to predicted capacity, $\kappa$, ranged from 0.35 to 0.90 with an average of 0.55 . Najjar (2005) also estimated that the lower bound capacity ratio ranged from 0.20 to 0.75 with an average of 0.50 for piles installed in sands.

Application of the findings by Najjar (2005) and Najjar and Gilbert (2009) could result in significant financial savings for appropriately calibrated code-based deep foundation design, and lower-bound capacity limits were determined for the proposed unit shaft and toe bearing resistance models and incorporated into resistance factor calibration. The lower-bound limit associated with the $\beta$-coefficient shown in Figure 1 was selected as the lower-bound capacity limit enveloping $\beta$-coefficients greater than 0.17 , and is equivalent to applying a constant value of $\kappa_{\beta}=0.35$ to the proposed design line. Although a more complex function could have been used to better encapsulate the observed data in the upper three meters, this approach would result in a non-constant $\kappa_{\beta}$, and introduce unnecessary complexity into the resistance factor calibrations. Owing to the typical depth of ACIP pile installation, the selection of the lower limit 
in this region is not critical to reliability-based analyses. Because very small $\beta$-coefficients are unlikely to occur at shallow depths (i.e. $z<3$ meters), and no values less than 0.17 were observed at depths less than 9.4 , the selection of a constant $\kappa_{\beta}$ is appropriate for the analysis conducted herein. Similarly, a lower-bound limit for unit toe bearing resistance was obtained by applying a $\kappa_{t}=0.35$ to the proposed design model (Eqn. 3, Figure 3).

Should some uncertainty exist, Najjar and Gilbert (2009) suggested that the probability of failure was not sensitive to variability in the lower bound capacity in the range of $C O V_{\kappa}$ of 0 to 30 percent. This finding was supported by assessing calibrated resistance factors using various levels of uncertainty in $\kappa$ as described subsequently. It should be noted that because the mean bias of a given distribution may not be exactly one, the actual lower bounds applied to the simulated shaft and toe bearing resistance bias distributions should not be set equal to $\kappa_{\beta}$ and $\kappa_{t}$, respectively. Instead, the lower-bound limits for shaft and toe bearing resistance bias that were used to calibrate resistance factors are equal to product of $\kappa_{\beta}$ and $\lambda_{\mu, s}$, and $\kappa_{t}$ and $\lambda_{\mu, t}$, respectively.

\section{Effect of Uncertainty in Lower-Bound Capacity on Resistance Factors}

It was considered worthwhile to investigate the effect of an uncertain lower bound limit, $\kappa$, on $\phi_{R}$. Because the proposed shaft and toe bearing resistance models are associated with markedly different levels of uncertainty (51.3 and 27.8 percent, respectively) and follow different distributions (i.e. lognormal and normal, respectively), both distributions were subjected to an uncertain lower bound limit in order to indirectly assess the impact of distribution uncertainty and type on $\phi_{R}$. Resistance factors were calculated for a $C O V_{\kappa}$ ranging from 0 to 50 percent (Fig. 5) using the lognormal and normal statistics for ultimate shaft and toe bearing resistance $\left(\lambda_{\mu, s}=1.00, C O V_{s}=51.3\right.$ percent and $\lambda_{\mu, t}=1.01, C O V_{t}=27.8$ percent $)$, AASHTOrecommended load statistics (Nowak 1999; AASHTO 2012), a target $\beta=2.33, \eta=3$, and a mean 
$\kappa=0.35$. The distribution of $\kappa$ was assumed to follow a normal distribution. In general, the uncertainty in $\kappa$ had a small effect on $\phi_{R}$, which ranged from 0.469 to 0.436 for shaft resistance and 0.547 to 0.554 for toe bearing resistance for $C O V_{\kappa}$ in the range of 0 to 50 percent (Figure 5). In general, an increase in $C O V_{\kappa}$ causes a decrease in $\phi_{R}$ for a mean $\kappa=0.35$ for shaft resistance, whereas a small increase in $\phi_{R}$ for the same $\kappa$ was observed for toe bearing resistance. This difference can be attributed to differences in uncertainty and shape of the lognormal and normal distributions near the point of the applied lower bound limit. Because $\phi_{R}$ is relatively unaffected by the presence of a lower-bound limit when $\kappa<0.40$ (Najjar and Gilbert 2009), smaller values in the uncertain lower-bound limit will have minimal effect on $\phi_{R}$.

\section{Resistance factors for Compressive Loading}

Resistance factors for shaft and toe bearing resistance for ACIP piles loaded in compression were calibrated using the ultimate shaft and toe bearing resistance bias statistics and the deterministic lower-bound resistance ratios. In order to adequately capture $p_{f}$, the number of independent realizations for each component in the limit state equation was set equal to 1,000,000 (corresponding to a confidence level of 94.2\%). Each realization was associated with two independent simulations for live and dead loads, which were modeled using the $\lambda_{Q}$ given by Eqn. (6). Figures $6 \mathrm{a}$ and $6 \mathrm{~b}$ show the variation of $\phi_{R}$ with $\eta$ for $\beta=2.33$ and 3.09 for a $\kappa=0.35$ for shaft and toe bearing resistance, respectively. In order to illustrate the effect of applying a lower-bound limit, resistance factors were calibrated without lower-bound limits. Overall, the increase in $\phi_{R}$ from applying the lower-bound limits ranged from 20 to 153 percent, depending on target level of reliability and dead to live load ratio, and represents a significant increase in useable pile capacity. Table 1 presents the power law parameters $(\psi, \alpha)$ for the curves shown in Figure 6, which allow resistance factors to be calculated for $\eta$ ranging from 1 to 10 . 
In general, the increase in useable resistance (i.e. $\phi_{R}$ ) from the application of a lower bound limit is proportional to the level of uncertainty in the resistance distribution that's being truncated. Because the shaft resistance model is more variable than the toe bearing resistance model, the impact of $\kappa$ on $\phi_{R}$ should be more pronounced for shaft resistance. Indeed, this is the case when $\beta=2.33$, where the increase in $\phi_{R}$ from the use of a lower bound limit is approximately eight percent higher for shaft resistance compared to toe bearing resistance. However, at a more stringent target probability of failure (i.e. $\beta=3.09$ ), the results herein suggest that the type of distribution (i.e. normal or lognormal) truncated by a lower bound limit has a larger impact on $\phi_{R}$ compared to its overall uncertainty, where the percent increase in $\phi_{R}$ from the use of a lower bound limit was nearly 100 percent larger for the normally distributed toe bearing resistance model with moderate to low variability $\left(C O V_{t}=27.8\right.$ percent $)$ compared to the lognormally distributed shaft resistance model with higher variability $\left(C O V_{s}=51.3\right.$ percent $)$.

The larger increase in $\phi_{R}$ for toe bearing resistance, despite a smaller degree of uncertainty (i.e. $C O V$ ), can be attributed to differences between the shape of the left tails of the normal and lognormal distributions, where the point biases are less than one, and the relationship with target reliability index. Because small probabilities of failure are typically specified in practice for the ULS, the extreme left tail of a resistance distribution will govern the results from resistance factor calibration efforts (Bathurst et al. 2008; Reddy and Stuedlein 2017). In addition, the magnitude or density of the distribution at and to the left of the point of truncation will influence $\phi_{R}$. For a consistent level of uncertainty, the left tail of a lognormal distribution is smaller than that of a normal distribution. As a result, the application of a lower bound limit will have a smaller impact on $\phi_{R}$ for a lognormal resistance distribution compared to a normal distribution with the same $C O V$. However, if the $C O V$ of the lognormal distribution is much larger than that 
of the normal distribution, the density of the lognormal distribution will be larger than the density of the normal distribution at the point of truncation. In this case, the application of a lower bound limit will have a greater impact on $\phi_{R}$, as illustrated by the calibration results discussed above when $\beta=2.33$. For the case of $2.33 \leq \beta \leq 3.09$, the type of resistance distribution has a greater effect on the increase in $\phi_{R}$ from the application of a lower bound limit than the variability implied by the distribution. These results illustrate the importance of selecting a statistical distribution that accurately models the empirical data when calibrating resistance factors, especially in the left tail where point bias are less than one.

\section{Resistance factors for Uplift Loading}

ULS resistance factors were calibrated for ACIP piles loaded in tension using the lognormal shaft resistance bias distribution statistics and lower-bound limits for shaft resistance $(\kappa=0.35)$, AASHTO live load statistics, and target reliability indices of 2.33 and 3.09. This approach assumes that all tensile loads develop from live sources, and ignores the resistance from gravity loads including self-weight; consequently, the calibrated resistance factors may be considered slightly conservative. The limit state function (Eqn. 5) was used to calibrate the resistance factors, however Eqns. (6) and (7) were assessed with $\eta=0$ (i.e., with no dead loads). Resistance factors for ACIP piles loaded in tension for target $\beta$ equal to 2.33 and 3.09 were 0.51 and 0.43 , respectively, and correspond to a confidence level of $97.8 \%$. For comparison, resistance factors for piles loaded in tension were also calibrated without lower-bound limits for target reliability indices of 2.33 and 3.09 and were equal to 0.41 and 0.28 , respectively. Owing primarily to the large variability in the proposed shaft resistance model, the inclusion of lowerbound limits in this case results in a 24 and 50 percent increase in $\phi_{R}$ for $\beta=2.33$ and 3.09 , respectively, and represents a significant increase in the amount of useable pile capacity. 


\section{SUMMARY AND CONCLUSIONS}

Revised design equations for estimating shaft and toe bearing resistance at the ultimate limit state (ULS) were proposed using a large database consisting of static loading tests performed on auger cast-in-place (ACIP) piles installed in predominately granular soils. The proposed ultimate shaft resistance model was developed using an effective stress approach, where the $\beta$ coefficient varies as a function of depth; the proposed unit toe bearing resistance model varies as a function of SPT $N_{1,60}$. Unlike previous models for ultimate unit shaft and toe bearing resistance, the proposed methodologies are unbiased such that the accuracy of the proposed models does not depend on the magnitude of predicted resistance.

Lower-bound limits for ultimate shaft and toe bearing resistance were developed using deterministic lower-bound resistance ratios, defined as the ratio of lower-bound capacity to predicted capacity. Resistance factors calibrated with lower-bound limits were relatively insensitive to variability in the lower-bound ratio. Resistance factors calibrated at the ULS associated with compressive loads for shaft and toe bearing resistance were expressed as a function of the dead to live load ratio, lower-bound capacity ratio, and reliability index. Resistance factors were also calibrated for piles loaded in tension. The application of a lower bound ratio equal to 0.35 resulted in a significant increase in resistance factors for piles loaded in tension and compression for both shaft and toe bearing resistance, where the percent increase in resistance factors for piles subjected to compressive loads ranged from 19.9 to 152.5 percent depending on the resistance distribution (i.e. shaft or toe bearing), selected dead to live load ratio, and target reliability index. The percent increase resulting from the lower-bound limit for resistance factors for piles loaded in tension was generally smaller ( 24 to 50 percent) compared to resistance factors calibrated for toe bearing resistance for compressive loads, yet represents a 
significant increase in the amount of useable pile capacity. Provided that a lower bound soil resistance model is developed based on justifiable soil mechanics principles, the application of a lower bound limit on the distribution of resistance can improve the overall estimate of foundation reliability, and is a useful way to reduce the discrepancy between the predicted and observed probabilities of failure.

Najjar (2005) showed that the impact of applying a lower bound limit on the estimated reliability of a system is directly dependent on the degree of uncertainty in the resistance distribution. In general, the findings in this study are consistent with Najjar (2005); however, the type of resistance distribution (i.e. normal, lognormal) was also shown to have a significant effect on $\phi_{R}$, and in some cases outweighed the effect of distribution uncertainty. It is noted that the resistance factors calibrated herein are only appropriate for ACIP piles installed in nonplastic granular soils representative of the database used in this study. The companion paper describes a corresponding RBD-methodology for the serviceability limit state, as well as an example illustrating the use of the methodologies developed in this study.

\subsection{REFERENCES}

Aggarwal, R.K., Litton, R.W., Cornell, C.A., Tang, W.H., Chen, J.H., and Murff, J.D. 1996.

Development of pile foundation bias factors using observed behavior of platforms during hurricane Andrew. In Proceedings of the Offshore Technology Conference, Houston, Texas, 6-9 May 1996. pp. 445-455.

Allen, T.M. 2005. Development of geotechnical resistance factors and downdrag load factors for LRFD foundation strength limit design. Federal Highway Administration Report FHWANHI-05-052, National Highway Institute, Washington, D.C. 
Allen, T.M. 2007. Development of new pile-driving formula and its calibration for load and resistance factor design. Transportation Research Record: Journal of the Transportation Research Board, 2004: 20-27.

Allen, T.M., Nowak, A.S., and Bathurst, R.J. 2005. Calibration to determine load and resistance factors for geotechnical and structural design. Transportation Research Board Circular EC079, Transportation Research Board, Washington, D.C.

American Association of State Highway and Transportation Officials (AASHTO). 2007. LRFD Bridge Design Specifications. 3rd ed. American Association of State Highway and Transportation Officials, Washington, D.C.

American Association of State Highway and Transportation Officials (AASHTO). 2012. LRFD Bridge Design Specifications. 6th ed. American Association of State Highway and Transportation Officials, Washington, D.C.

American Petroleum Institute (API). 1993. API RP 2A-LRFD: Recommended practice for planning, designing and construction fixed offshore platforms - Load and resistance factor design, 1st ed. American Petroleum Institute, Washington, D.C.

Basu, D., and Salgado, R. 2012. Load and resistance factor design of drilled shafts in sand. Journal of Geotechnical and Geoenvironmental Engineering, 138(12): 1455-1469.

Bathurst, R.J., Allen, T.M., and Nowak, A.S. 2008. Calibration concepts for load and resistance factor design (LRFD) of reinforced soil walls. Canadian Geotechnical Journal, 45(10): 13771392.

Bathurst, R.J., Huang, B.Q., and Allen, T.M. 2011. LRFD Calibration of Steel Reinforced Soil Walls. Geo-Frontiers 2011: 3429-3438. 
Bea, R.G., Jin, Z., Valle, C., and Ramos, R. 1999. Evaluation of reliability of platform pile foundations. Journal of Geotechnical and Geoenvironmental Engineering, 125(8): 696-704.

Bond, A.J., and Jardine, R.J. 1995. Shaft capacity of displacement piles in a high OCR clay. Geotechnique, 45(1): 3-23.

Bond, A.J., Jardine, R.J., and Lehane, B.M. 1993. Factors affecting the shaft capacity of displacement piles in clays. In Proceedings of the Offshore Site Investigation and Foundation Behavior Conference, London, United Kingdom, 22-24 September, Society for Underwater Technology, London, pp. 585-606.

Brown, D.A., Dapp, S.D., Thompson, W.R., and Lazarte, C.A. 2007. Design and construction of continuous flight auger piles. Geotechnical Engineering Circular 8, Federal Highway Administration, Washington, D.C.

Chin, F.K., and Vail, A.J. 1973. Behavior of piles in alluvium. In Proceedings of the 8th International Conference on Soil Mechanics and Foundation Engineering, Moscow, Russia, 4-6 July, Kluwer, The Netherlands, Volume 2, pp. 47-52.

Ching, J., Phoon, K., Chen, J., and Park, J. 2013. Robustness of constant load and resistance factor design factors for drilled shafts in multiple strata. Journal of Geotechnical and Geoenvironmental Engineering, 139(7): 1104-1114.

Deep Foundation Institute (DFI). June 2013. Corvallis, OR.

Douglas, D.J. 1983. Discussion on paper 17-22: case histories. In Proceedings of the Conference on Piling and Ground Treatment, Institution of Civil Engineers, London, pp. 283.

Federal Highway Administration (FHWA). 2007. Clarification of LRFD policy memorandum, Memorandum, Federal Highway Administration, United States Department of Transportation, dated January 27, 2007. 
Fellenius, B. H. 2002. Discussion of Side Resistance in Piles and Shafts. Journal of Geotechnical and Geoenvironmental Engineering, 128(5): 446 - 448 .

Gurtowski, T.M. 1997. Augercast pile design in northwest glacial soils. In Proceedings of the 14th Annual Spring Seminar, ASCE Seattle Section Geotechnical Group, Seattle, Washington, American Society of Civil Engineers, Virginia, pp. 1-20.

Hirany, A., and Kulhawy, F.H. 1988. Conduct and interpretation of load tests on drilled shaft foundations, volume 1: detailed guidelines. Electric Power Research Institute Report EL5915-V1, Electric Power Research Institute, Palo Alto, CA.

Horsnell, M.R., and Toolan, F.E. 1996. Risk of foundation failure of offshore jacket piles. In Proceedings of the Offshore Technology Conference, Houston, Texas, 6-9 May 1996, pp. 381-392.

Kraft, L.M., Ray, R.P., and Kagawa, T. 1981. Theoretical t-z curves. Journal of Geotechnical Engineering Division, 107(11): 1543-1561.

Kulhawy, F.H. 1991. Drilled shaft foundations. In Foundation Engineering Handbook, 2nd ed. Edited by H.Y. Fang. Chapman and Hall, New York, pp. 537-552.

Kulhawy, F.H. 2004. On the axial behavior of drilled foundations. In GeoSupport: Drilled Shafts, Micropiling, Deep Mixing, Remedial Methods, and Specialty Foundation Systems, Geotechnical Special Publication 124, Orlando, Florida, 29-31 December 2004. American Society of Civil Engineers, Virginia, pp. 1-18.

Kulhawy, F.H., and Phoon, K.K. 2006. Some critical issues in Geo-rbd calibrations for foundations. In GeoCongress: Geotechnical Engineering in the Information Technology Age, Atlanta, Georgia, 26 February-1 March 2006. American Society of Civil Engineers, Virginia, pp. 1-6. 
Mandolini, A., Ramondini, M., Russo, G., and Viggiani, C. 2002. Full scale loading tests on instrumented CFA piles. In Deep Foundations: An International Perspective on Theory, Design, Construction, and Performance, Geotechnical Special Publication 116, Orlando, Florida, 14-16 February 2002. American Society of Civil Engineers, Virginia, pp. 10881097.

McCarthy, D.J. 2008. Empirical relationships between load test data and predicted compression capacity of augered cast-in-place piles in predominately cohesionless soils. M.S. Thesis, Department of Civil, Environmental, and Construction Engineering, The University of Central Florida, Orlando, FL.

McVay, M., Armaghani, B., and Casper R. 1994. Design and construction of auger cast piles in Florida. Transportation Research Record: Journal of the Transportation Research Board, 1447: 10-18.

Meyerhof, G.G. 1976. Bearing capacity and settlement of pile foundations. Journal of Geotechnical Engineering Division, 102(3): 195-228.

Najjar, S.S. 2005. The importance of lower-bound capacities in geotechnical reliability assessments. Ph.D. Dissertation, The University of Texas at Austin, Austin, TX.

Najjar, S.S., and Gilbert, R.B. 2009. Importance of lower-bound capacities in the design of deep foundations. Journal of Geotechnical and Geoenvironmental Engineering, 135(7): 890-900.

Naval Facilities Engineering Command (NAVFAC). 1986. Foundations and earth structures. Design Manual 7.02, US Department of the Navy, Alexandria, VA.

Neely, W.J. 1991. Bearing capacity of auger-cast piles in sand. Journal of Geotechnical and Geoenvironmental Engineering, 117(2): 331-346. 
Nowak, A.S. 1999. Calibration of LRFD bridge design code. National Cooperative Highway Research Program Report 368, Transportation Research Board, National Research Council, Washington, D.C.

O’Dell, L.G., and Pool, J.M. 1979. Auger-placed grout piles in gravel. In Proceedings of the Symposium on Deep Foundations, Atlanta, Georgia, 25 October 1979. American Society of Civil Engineers, Virginia, pp. 300-310.

O’Neill, M.W. 1994. Review of augered pile practice outside the United States. Transportation Research Record: Journal of the Transportation Research Board, 1447: 3-9.

O’Neill, M.W., and Reese, L.C. 1999. Drilled shafts: construction procedures and design methods. Federal Highway Administration Report FHWA-IF-99-025, Federal Highway Administration, Washington, D.C.

O’Neill, M.W., Vipulanandan, C., Ata, A., and Tan, F. 1999. Axial performance of continuous flight auger piles for bearing. Texas Department of Transportation Report 7-3940-2, Texas Department of Transportation, Austin, Texas.

Paikowsky, S. G., with contributions from Birgisson, B., McVay, M.C., Nguyen, T., Kuo, C., Baecher, G., Ayyab, B., Stenersen, K., O’Malley, K., Chernauskas, L. and O’Neill, M.W. 2004. Load and resistance factor design (LRFD) for deep foundations. National Cooperative Highway Research Program Report 507, Transportation Research Board, National Research Council, Washington, D.C.

Park, S., Roberts, L.A., and Misra, A. 2010. Characterization of t-z parameters and their variability for auger pressure grouted piles using field load test data. In GeoFlorida: Advances in Analysis, Modeling, and Design, Geotechnical Special Publication 199, 
Orlando, Florida, 20-24 February 2010. American Society of Civil Engineers, Virginia, pp. $1757-1766$.

Park, S., Roberts, L.A., and Misra, A. 2012. Design methodology for axially loaded auger castin-place (ACIP) and drilled displacement (DD) piles. Journal of Geotechnical and Geoenvironmental Engineering, 138(12): 1431-1441.

Phoon, K., Kulhawy, F., and Grigoriu, M. 2003. Development of a reliability-based design framework for transmission line structure foundations. Journal of Geotechnical and Geoenvironmental Engineering, 129(9): 798-806.

Prezzi, M., and Basu, P. 2005. Overview of construction and design of auger cast-in-place and drilled displacement piles. In the Proceedings of the 30th Annual Conference on Deep Foundations, Chicago, Illinois, 22-24 September 2005. Deep Foundations Institute, New Jersey, pp. 497-512.

Reddy, S.C., and Stuedlein, A.W. 2013. Accuracy and reliability-based region-specific recalibration of dynamic pile formulas. Georisk: Assessment and Management of Risk for Engineered Systems and Geohazards, 7(3): 163-183.

Reddy, S.C., and Stuedlein, A.W. 2016. Serviceability limit state reliability-based design of augered cast-in-place piles in granular soils. Canadian Geotechnical Journal, Accepted Feb.3, 2017.

Reddy, S.C., and Stuedlein, A.W. 2017. Impact of Resistance Distribution Selection on Foundation Reliability in Consideration of Lower-bound Limits. Georisk 2017, Denver, CO, 4- 6 June 2017. 14 pp.

Simpson, B., Pappin, J.W., and Croft, D.D. 1981. An approach to limit state calculations in geotechnics. Ground Engineering, 14(6): 21-28. 
Stuedlein, A.W., and Reddy, S.C. 2013. Factors affecting the reliability of augered cast-in-place piles in granular soils at the serviceability limit state. Journal of the Deep Foundations Institute, 7(2): 46-57.

Stuedlein, A.W., Neely, W.J., and Gurtowski, T.M. 2012. Reliability-based design of augered cast-in-place piles in granular soils. Journal of Geotechnical and Geoenvironmental Engineering, 138(6): 709-717.

Stuedlein, A.W., Neely, W.J., and Gurtowski, T.M. 2013. Erratum for Reliability-based design of augered cast-in-place piles in granular soils. Journal of Geotechnical and Geoenvironmental Engineering, 139(11): 2005-2006.

van den Elzen, L.W.A 1979. Concrete screw piles, a vibrationless, non-displacement piling method. In Proceedings of the Conference on Recent Developments in the Design and Construction of Piles, London, United Kingdom, 21-22 March 1979. Institution of Civil Engineers, London, pp. 67-71.

Vijayvergiya, V.N. 1977. Load-movement characteristics of piles. In Proceedings of the 4th Annual Symposium of the Waterway, Port, Coastal, and Ocean Division of ASCE Vol. 2, Long Beach, California, 9-11 March 1977. American Society of Civil Engineers, Virginia, pp. 269-284.

Vipulanandan, C. 2007. Recent advances in designing, monitoring, modeling, and testing deep foundations in North America. In Proceedings of Advances in Deep Foundations: International Workshop on Recent Advances of Deep Foundations, Yokosuka, Japan, 1-2 February 2007. Taylor and Francis Group, London, pp. 87-100.

Wright, S.J., and Reese, L.C. 1979. Design of large diameter bored piles. Ground Engineering, 12(8): $17-50$. 


\section{Figure Captions}

Fig. 1. Proposed design model and associated lower-bound limit for estimating the $\beta$-coefficient with depth for ACIP piles in granular soils. NSPT $>15$ assumed for the FHWA design model for plotting purposes.

Fig. 2. Variation in model bias with nominal pile resistance (a) comparison of the proposed and FHWA $\beta$-coefficient models, and (b) comparison of the proposed and FHWA unit toe bearing resistance models.

Fig. 3. The proposed design model and lower-bound limit for unit toe bearing resistance with SPT $\mathrm{N}_{1,60}$ for ACIP piles in granular soils. The mean bias and COV for the proposed unit toe bearing resistance model are 1.01 and 27.8 percent, respectively.

Fig. 4. Empirical, normal, and lognormal cumulative distribution functions in standard normal space for the (a) shaft resistance bias, and (b) the toe bearing resistance bias.

Fig. 5. Effect of uncertainty in the lower-bound resistance ratio, COVк, applied to distributions of shaft and toe resistance on the resistance factor, $\phi_{R}$, for a mean $\kappa=0.35, \eta=3, \beta=$ 2.33 .

Fig. 6. The variation of resistance factors with the ratio of dead to live load for ACIP piles loaded in compression: (a) resistance factors for shaft resistance, and (b) resistance factors for toe bearing resistance. 


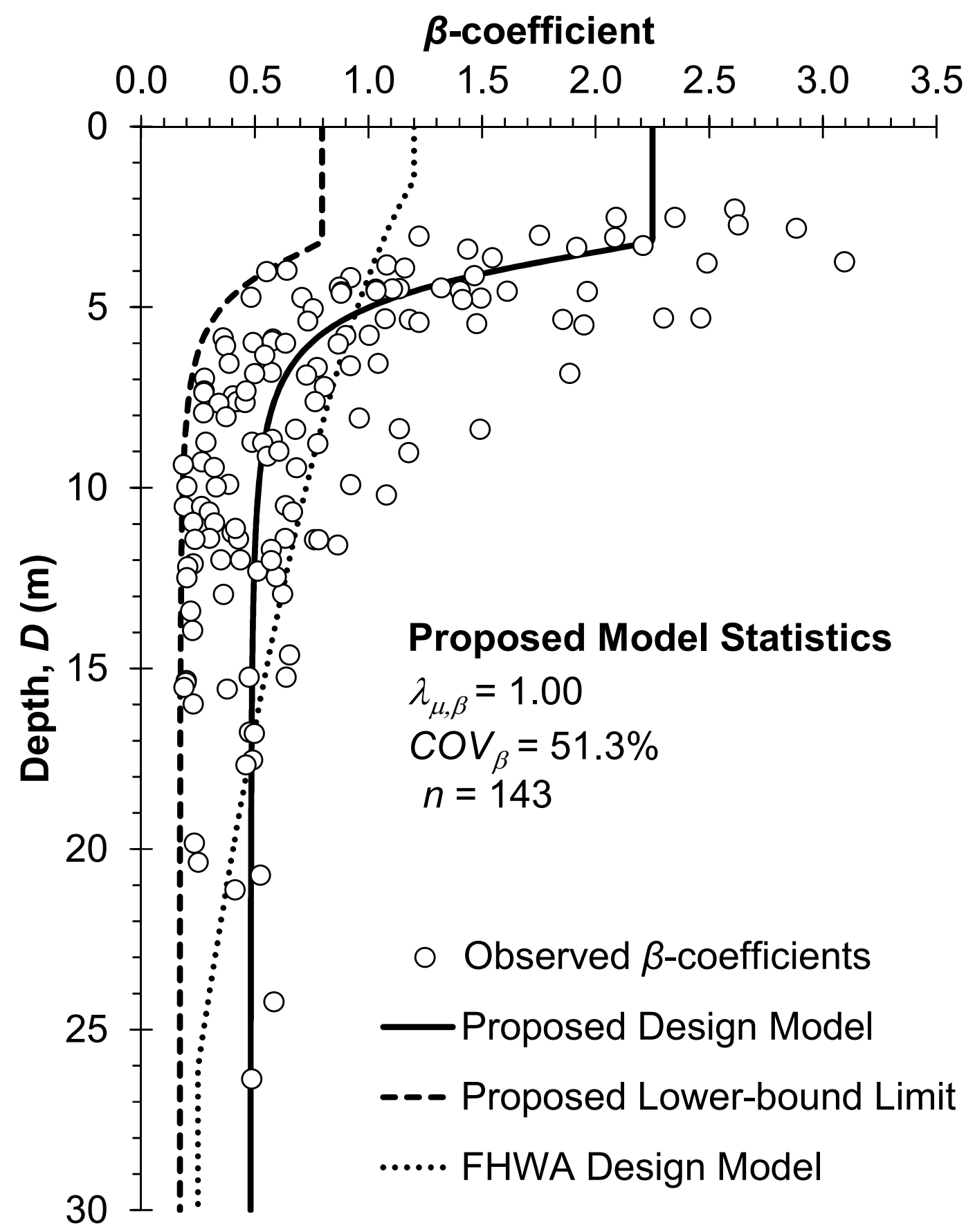

Fig. 1. Proposed design model and associated lower-bound limit for estimating the $\beta$-coefficient with depth for ACIP piles in granular soils. $N_{S P T}>15$ assumed for the FHWA design model for plotting purposes. 

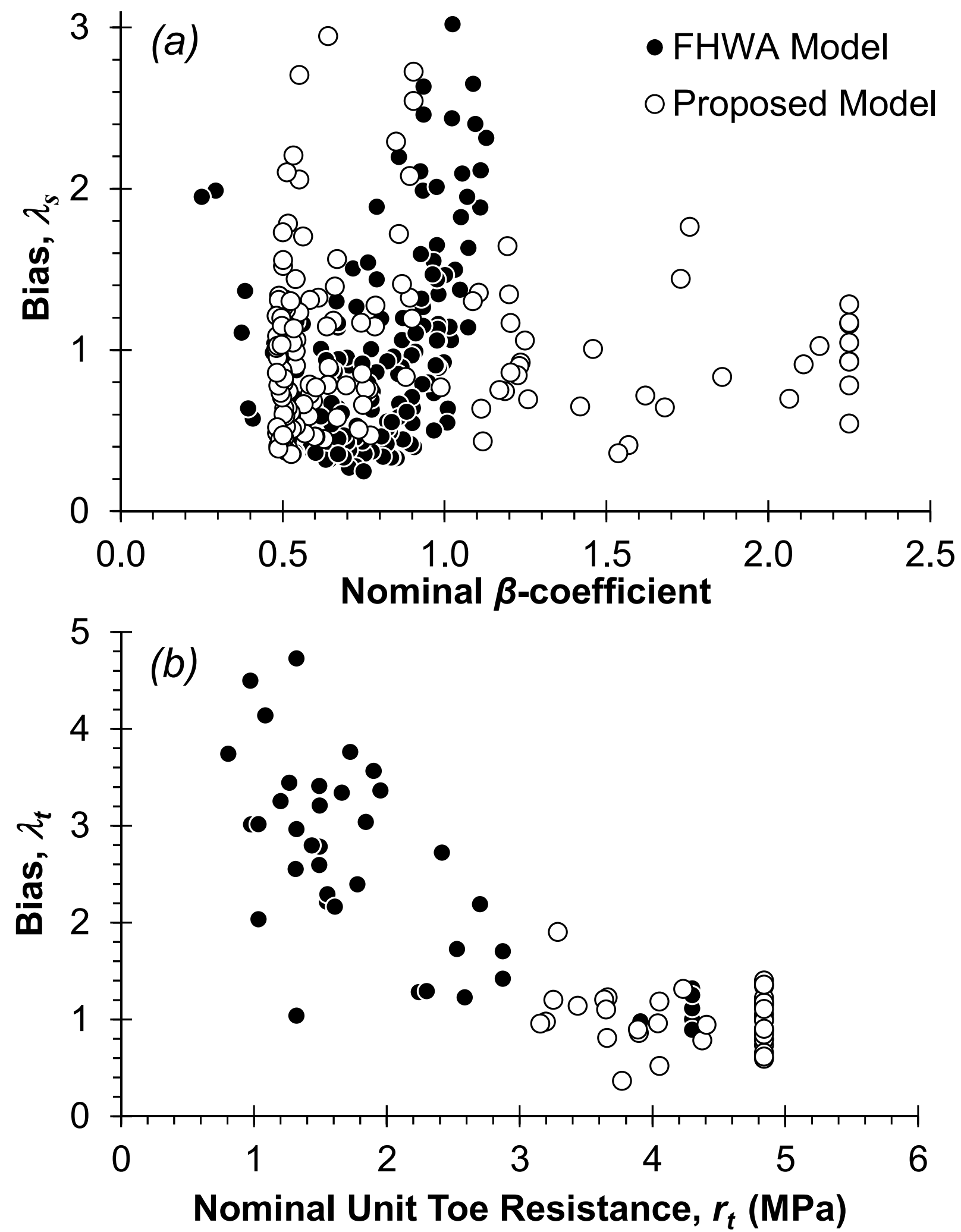

Fig. 2. Variation in model bias with nominal pile resistance (a) comparison of the proposed and FHWA $\beta$-coefficient models, and (b) comparison of the proposed and FHWA unit toe bearing resistance models. 


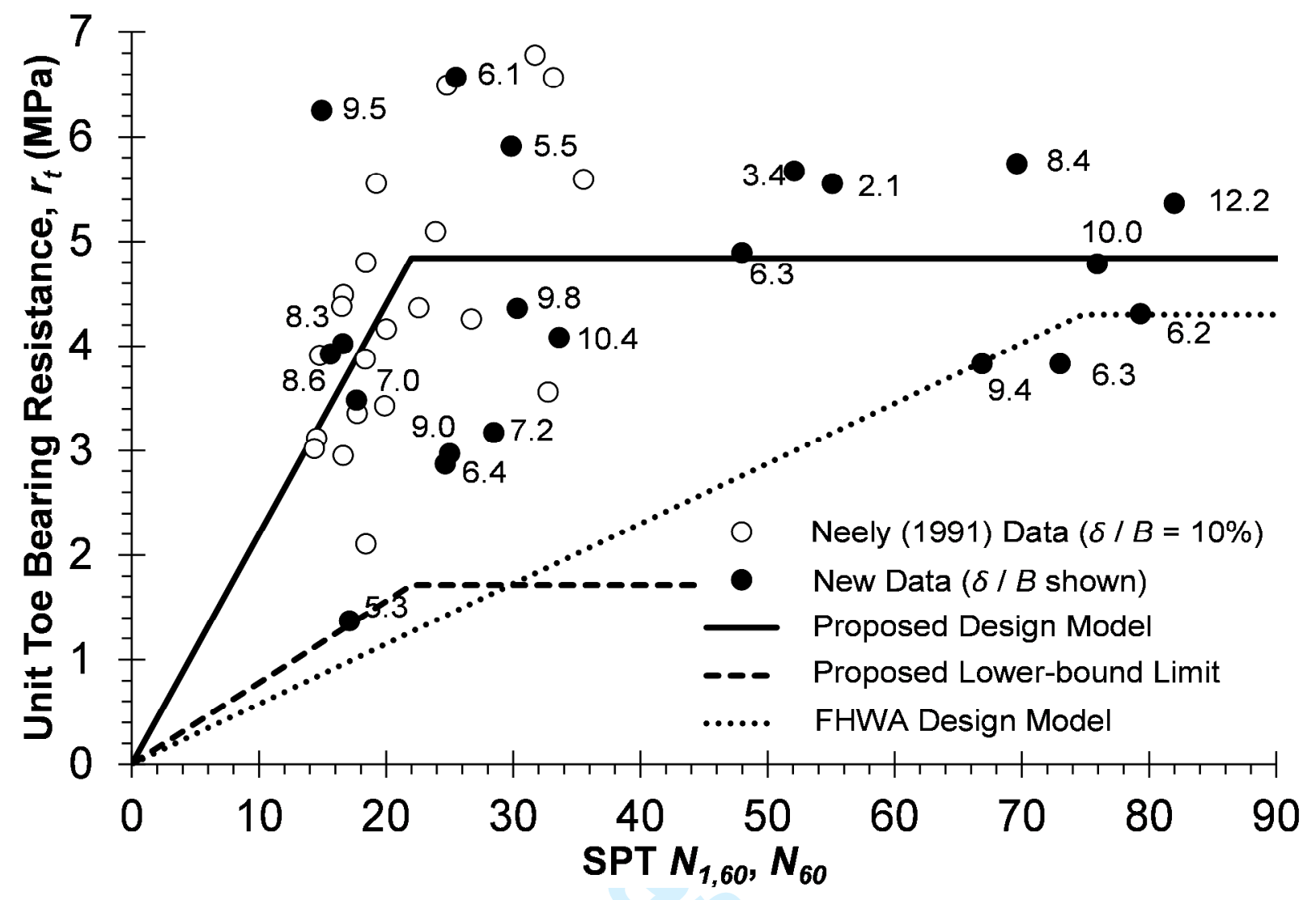

Fig. 3. The proposed design model and lower-bound limit for unit toe bearing resistance with SPT $N_{1,60}$ for ACIP piles in granular soils. The mean bias and COV for the proposed unit toe bearing resistance model are 1.01 and 27.8 percent, respectively. 

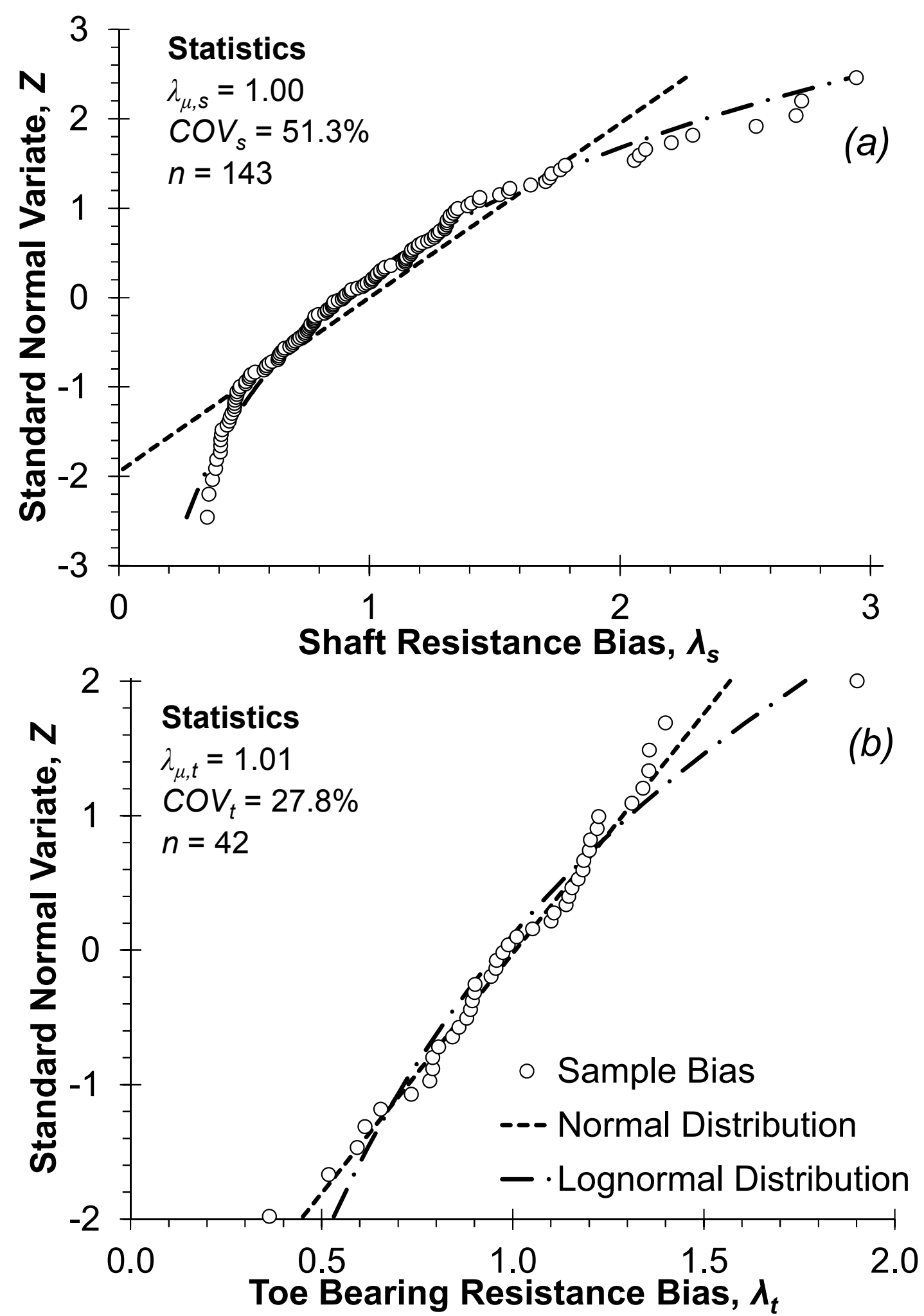

Fig. 4. Empirical, normal, and lognormal cumulative distribution functions in standard normal space for the (a) shaft resistance bias, and (b) the toe bearing resistance bias. 


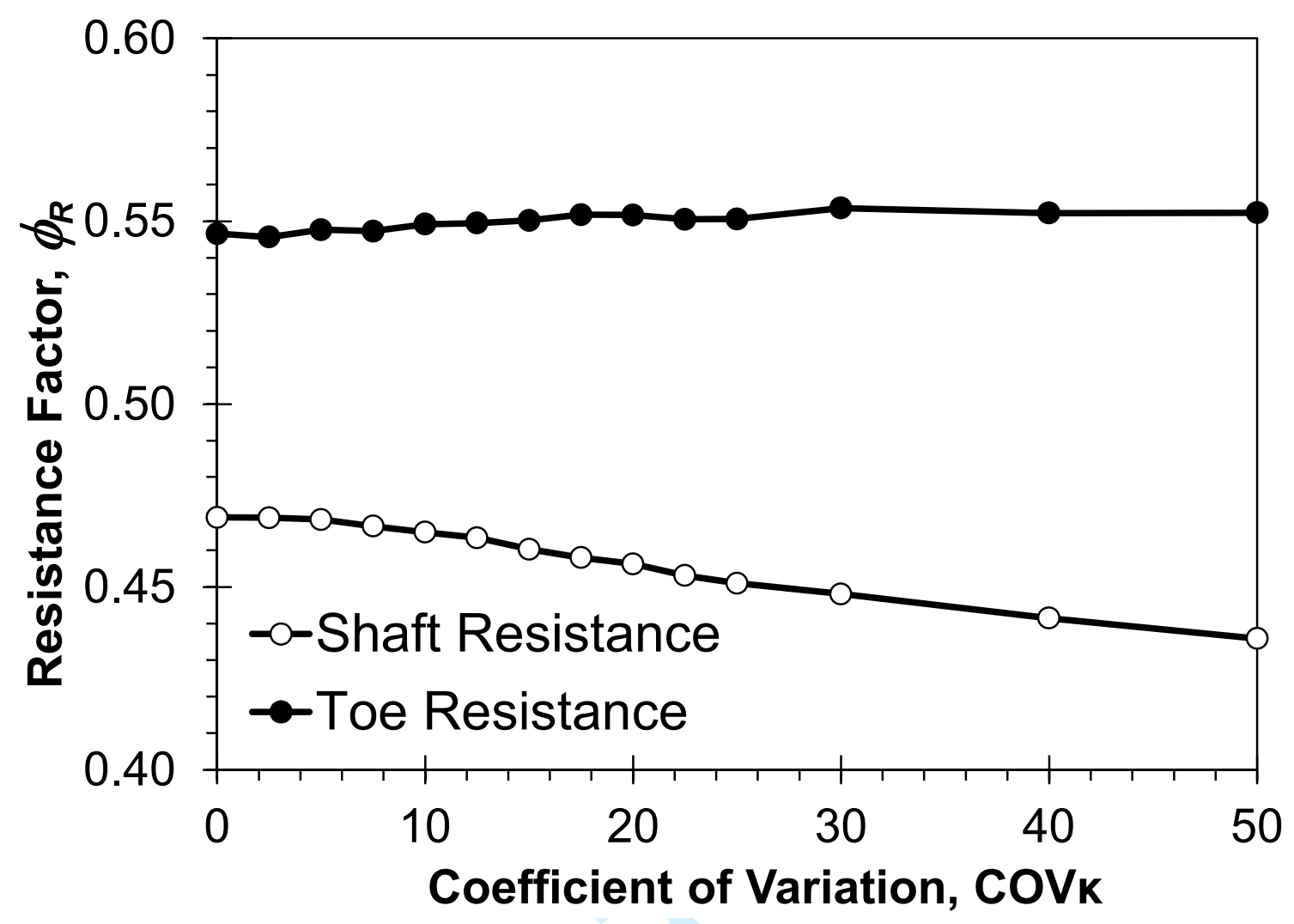

Fig. 5. Effect of uncertainty in the lower-bound resistance ratio, $C O V_{\kappa}$, applied to distributions of shaft and toe resistance on the resistance factor, $\phi_{R}$, for a mean $\kappa=0.35, \eta=3, \beta=2.33$. 


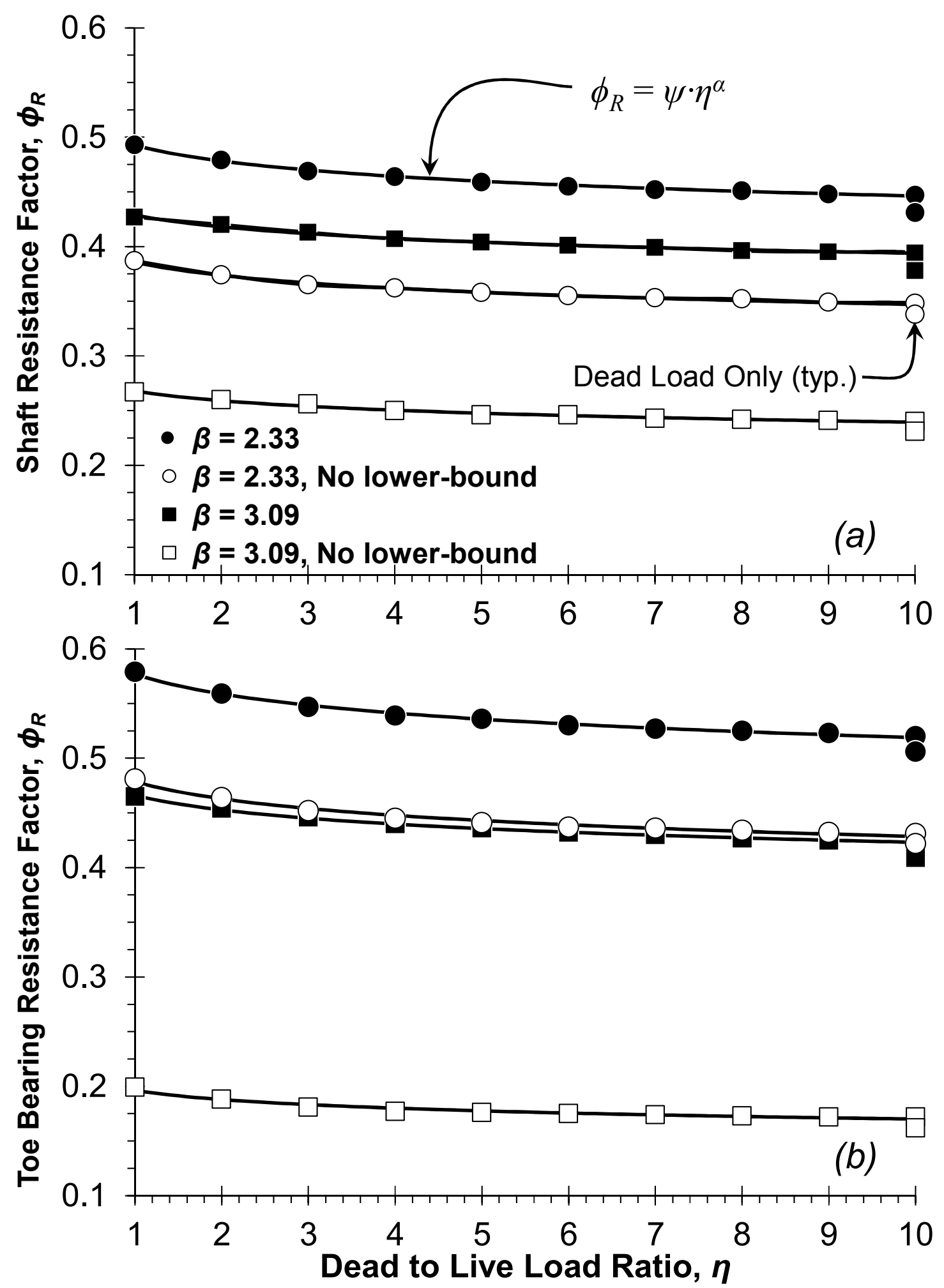

Fig. 6. The variation of resistance factors with the ratio of dead to live load for ACIP piles loaded in compression: (a) resistance factors for shaft resistance, and (b) resistance factors for toe bearing resistance. 
Table 1. The parameters associated with the power law model (Fig. 6 and 7) to estimate resistance factors for piles loaded in compression for shaft and toe bearing resistance for different dead to live load ratios and target reliability indices.

\begin{tabular}{ccccc}
\hline Resistance & Target $\beta$ & Lower-bound ratio, $\kappa_{T}$ & $\psi$ & $\alpha$ \\
\hline Shaft & 2.33 & 0.35 & 0.493 & -0.043 \\
Shaft & 2.33 & No lower-bound & 0.386 & -0.046 \\
Shaft & 3.09 & 0.35 & 0.429 & -0.037 \\
Shaft & 3.09 & No lower-bound & 0.268 & -0.049 \\
\hline Toe & 2.33 & 0.35 & 0.577 & -0.046 \\
Toe & 2.33 & No lower-bound & 0.479 & -0.048 \\
Toe & 3.09 & 0.35 & 0.466 & -0.042 \\
Toe & 3.09 & No lower-bound & 0.196 & -0.062 \\
\hline
\end{tabular}




\section{Appendix}

Table A1. Database used to develop revised shaft and toe bearing resistance models and to calibrate resistance factors for ACIP piles loaded in compression and tension. Data was variously admitted or rejected for a particular purpose depending on the quality and quantity of information available for each purpose.

\begin{tabular}{|c|c|c|c|c|c|c|c|c|}
\hline $\begin{array}{c}\text { Pile } \\
\text { Designation } \\
\text { No. }\end{array}$ & $\begin{array}{l}\text { Diameter, } \\
B(\mathrm{~mm})\end{array}$ & $\begin{array}{c}\text { Length, } \\
D(\mathrm{~m})\end{array}$ & $\begin{array}{l}\text { Instru- } \\
\text { mented }\end{array}$ & $\begin{array}{l}\text { Shaft } \\
\text { Resistance } \\
(\mathrm{kN})\end{array}$ & $\begin{array}{c}\text { Toe } \\
\text { Bearing } \\
\text { Resistance } \\
(\mathrm{kN})\end{array}$ & $\begin{array}{l}\text { Used for } \\
\text { Shaft } \\
\text { Resistance } \\
\text { Model }\end{array}$ & $\begin{array}{l}\text { Used for } \\
\text { Toe } \\
\text { Bearing } \\
\text { Resistance } \\
\text { Model }\end{array}$ & $\begin{array}{c}\text { Reference } \\
\text { No. }\end{array}$ \\
\hline 1 & 405 & 13.7 & $\mathrm{~N}$ & 632 & 549 & $\mathrm{Y}$ & $\mathrm{Y}$ & 1 \\
\hline 2 & 451 & 12.0 & $\mathrm{~N}$ & 591 & 814 & $\mathrm{Y}$ & $\mathrm{Y}$ & 1 \\
\hline 3 & 509 & 15.2 & $\mathrm{~N}$ & 647 & 1321 & $\mathrm{Y}$ & $\mathrm{Y}$ & 1 \\
\hline 4 & 405 & 8.2 & $\mathrm{~N}$ & 603 & 875 & $\mathrm{Y}$ & $\mathrm{Y}$ & 1 \\
\hline 5 & 405 & 13.1 & $\mathrm{~N}$ & 1239 & 579 & $\mathrm{Y}$ & $\mathrm{Y}$ & 1 \\
\hline 6 & 600 & 17.5 & $\mathrm{~N}$ & 961 & 1141 & $\mathrm{Y}$ & $\mathrm{Y}$ & 1 \\
\hline 7 & 600 & 17.5 & $\mathrm{~N}$ & 1001 & 1358 & $\mathrm{Y}$ & $\mathrm{Y}$ & 1 \\
\hline 8 & 600 & 16.0 & $\mathrm{~N}$ & 1101 & 971 & $\mathrm{Y}$ & $\mathrm{Y}$ & 1 \\
\hline 9 & 600 & 20.0 & $\mathrm{~N}$ & 1081 & 1573 & $\mathrm{Y}$ & $\mathrm{Y}$ & 1 \\
\hline 10 & 600 & 17.5 & $\mathrm{~N}$ & 1922 & 1096 & $\mathrm{Y}$ & $\mathrm{Y}$ & 1 \\
\hline 11 & 405 & 15.2 & $\mathrm{~N}$ & 1173 & 537 & $\mathrm{Y}$ & $\mathrm{Y}$ & 1 \\
\hline 12 & 405 & 14.6 & $\mathrm{~N}$ & 469 & 433 & $\mathrm{Y}$ & $\mathrm{Y}$ & 1 \\
\hline 13 & 305 & 9.1 & $\mathrm{~N}$ & 576 & 408 & $\mathrm{Y}$ & $\mathrm{Y}$ & 1 \\
\hline 14 & 305 & 7.6 & $\mathrm{~N}$ & 270 & 260 & $\mathrm{Y}$ & $\mathrm{Y}$ & 1 \\
\hline 15 & 610 & 20.0 & $\mathrm{~N}$ & 899 & 1274 & $\mathrm{Y}$ & $\mathrm{Y}$ & 1 \\
\hline 16 & 509 & 13.3 & $\mathrm{~N}$ & 956 & 614 & $\mathrm{Y}$ & $\mathrm{Y}$ & 1 \\
\hline 17 & 558 & 19.9 & $\mathrm{~N}$ & 1124 & 761 & $\mathrm{Y}$ & $\mathrm{Y}$ & 1 \\
\hline 18 & 405 & 9.0 & $\mathrm{~N}$ & 579 & 273 & $\mathrm{Y}$ & $\mathrm{Y}$ & 1 \\
\hline 19 & 399 & 9.5 & $\mathrm{~N}$ & 1084 & 369 & $\mathrm{Y}$ & $\mathrm{Y}$ & 1 \\
\hline 20 & 399 & 9.5 & $\mathrm{~N}$ & 1023 & 547 & $\mathrm{Y}$ & $\mathrm{Y}$ & 1 \\
\hline 21 & 399 & 9.5 & $\mathrm{~N}$ & 501 & 820 & $\mathrm{Y}$ & $\mathrm{Y}$ & 1 \\
\hline 22 & N/A & N/A & $\mathrm{N}$ & N/A & $\mathrm{N} / \mathrm{A}$ & $\mathrm{Y}$ & $\mathrm{N}$ & 1 \\
\hline 23 & $\mathrm{~N} / \mathrm{A}$ & N/A & $\mathrm{N}$ & N/A & N/A & $\mathrm{Y}$ & $\mathrm{N}$ & 1 \\
\hline 24 & N/A & N/A & $\mathrm{N}$ & N/A & N/A & $\mathrm{Y}$ & $\mathrm{N}$ & 1 \\
\hline 25 & N/A & $\mathrm{N} / \mathrm{A}$ & $\mathrm{N}$ & N/A & N/A & $\mathrm{Y}$ & $\mathrm{N}$ & 1 \\
\hline 26 & N/A & N/A & $\mathrm{N}$ & N/A & N/A & $\mathrm{Y}$ & $\mathrm{N}$ & 1 \\
\hline \multirow[t]{2}{*}{27} & N/A & N/A & $\mathrm{N}$ & N/A & N/A & $\mathrm{Y}$ & $\mathrm{N}$ & 1 \\
\hline & N/A & N/A & $\mathrm{N}$ & N/A & N/A & $\mathrm{Y}$ & $\mathrm{N}$ & 1 \\
\hline 29 & N/A & N/A & $\mathrm{N}$ & N/A & N/A & $\mathrm{Y}$ & $\mathrm{N}$ & 1 \\
\hline
\end{tabular}




\begin{tabular}{|c|c|c|c|c|c|c|c|}
\hline 30 & N/A & N/A & $\mathrm{N}$ & N/A & N/A & $\mathrm{Y}$ & $\mathrm{N}$ \\
\hline 31 & N/A & $\mathrm{N} / \mathrm{A}$ & $\mathrm{N}$ & N/A & N/A & $\mathrm{Y}$ & $\mathrm{N}$ \\
\hline 32 & N/A & N/A & $\mathrm{N}$ & N/A & N/A & $\mathrm{Y}$ & $\mathrm{N}$ \\
\hline 33 & $\mathrm{~N} / \mathrm{A}$ & N/A & $\mathrm{N}$ & N/A & N/A & $\mathrm{Y}$ & $\mathrm{N}$ \\
\hline 34 & $\mathrm{~N} / \mathrm{A}$ & N/A & $\mathrm{N}$ & N/A & N/A & $\mathrm{Y}$ & $\mathrm{N}$ \\
\hline 35 & N/A & N/A & $\mathrm{N}$ & N/A & N/A & $\mathrm{Y}$ & $\mathrm{N}$ \\
\hline 36 & N/A & N/A & $\mathrm{N}$ & N/A & N/A & $\mathrm{Y}$ & $\mathrm{N}$ \\
\hline 37 & N/A & $\mathrm{N} / \mathrm{A}$ & $\mathrm{N}$ & N/A & N/A & $\mathrm{Y}$ & $\mathrm{N}$ \\
\hline 38 & N/A & N/A & $\mathrm{N}$ & N/A & N/A & $\mathrm{Y}$ & $\mathrm{N}$ \\
\hline 39 & N/A & N/A & $\mathrm{N}$ & N/A & N/A & $\mathrm{Y}$ & $\mathrm{N}$ \\
\hline 40 & N/A & N/A & $\mathrm{N}$ & N/A & N/A & $\mathrm{Y}$ & $\mathrm{N}$ \\
\hline 41 & N/A & N/A & $\mathrm{N}$ & N/A & N/A & $\mathrm{Y}$ & $\mathrm{N}$ \\
\hline 42 & N/A & N/A & $\mathrm{N}$ & N/A & N/A & $\mathrm{Y}$ & $\mathrm{N}$ \\
\hline 43 & N/A & N/A & $\mathrm{N}$ & N/A & N/A & $\mathrm{Y}$ & $\mathrm{N}$ \\
\hline 44 & N/A & N/A & $\mathrm{N}$ & N/A & N/A & $\mathrm{Y}$ & $\mathrm{N}$ \\
\hline 45 & N/A & N/A & $\mathrm{N}$ & N/A & N/A & $\mathrm{Y}$ & $\mathrm{N}$ \\
\hline 46 & N/A & N/A & $\mathrm{N}$ & N/A & N/A & $\mathrm{Y}$ & $\mathrm{N}$ \\
\hline 47 & N/A & N/A & $\mathrm{N}$ & N/A & $\mathrm{N} / \mathrm{A}$ & $\mathrm{Y}$ & $\mathrm{N}$ \\
\hline 48 & N/A & N/A & $\mathrm{N}$ & N/A & N/A & $\mathrm{Y}$ & $\mathrm{N}$ \\
\hline 49 & N/A & N/A & $\mathrm{N}$ & N/A & N/A & $\mathrm{Y}$ & $\mathrm{N}$ \\
\hline 50 & N/A & N/A & $\mathrm{N}$ & N/A & N/A & $\mathrm{Y}$ & $\mathrm{N}$ \\
\hline 51 & $\mathrm{~N} / \mathrm{A}$ & N/A & $\mathrm{N}$ & $\mathrm{N} / \mathrm{A}$ & N/A & $\mathrm{Y}$ & $\mathrm{N}$ \\
\hline 52 & 406 & 9.4 & $\mathrm{~N}$ & 734 & 635 & $\mathrm{Y}$ & $\mathrm{Y}$ \\
\hline 53 & 406 & 9.4 & $\mathrm{~N}$ & 1183 & 559 & $\mathrm{Y}$ & $\mathrm{Y}$ \\
\hline 54 & 406 & 14.9 & $\mathrm{~N}$ & 2391 & 497 & $\mathrm{Y}$ & $\mathrm{Y}$ \\
\hline 55 & 406 & 21.3 & $\mathrm{~N}$ & 2621 & 497 & $\mathrm{Y}$ & $\mathrm{Y}$ \\
\hline 56 & 406 & 12.2 & $\mathrm{~N}$ & 1919 & 621 & $\mathrm{Y}$ & $\mathrm{Y}$ \\
\hline 57 & 457 & 10.4 & $\mathrm{~N}$ & 2487 & 943 & $\mathrm{Y}$ & $\mathrm{Y}$ \\
\hline 58 & 457 & 29.0 & Y & 2822 & 970 & $\mathrm{Y}$ & $\mathrm{Y}$ \\
\hline 59 & 457 & 29.0 & $\mathrm{Y}$ & 3319 & 471 & $\mathrm{Y}$ & $\mathrm{Y}$ \\
\hline 60 & 508 & 21.9 & Y & 1877 & 1124 & $\mathrm{Y}$ & $\mathrm{Y}$ \\
\hline 61 & 508 & 23.9 & $\mathrm{Y}$ & 2049 & 1149 & $\mathrm{Y}$ & $\mathrm{Y}$ \\
\hline 62 & 406 & 21.3 & $\mathrm{Y}$ & 1715 & 809 & $\mathrm{Y}$ & $\mathrm{Y}$ \\
\hline 63 & 406 & 15.9 & $\mathrm{Y}$ & 1627 & 177 & $\mathrm{Y}$ & $\mathrm{Y}$ \\
\hline 64 & 406 & 19.8 & $\mathrm{Y}$ & 2334 & 507 & $\mathrm{Y}$ & $\mathrm{Y}$ \\
\hline 65 & 406 & 22.9 & $\mathrm{Y}$ & 2923 & 850 & $\mathrm{Y}$ & $\mathrm{Y}$ \\
\hline
\end{tabular}




\begin{tabular}{|c|c|c|c|c|c|c|c|}
\hline 66 & 406 & 22.4 & $\mathrm{Y}$ & 3040 & 450 & $\mathrm{Y}$ & $\mathrm{Y}$ \\
\hline 67 & 406 & 19.8 & $\mathrm{Y}$ & 834 & 520 & $\mathrm{Y}$ & $\mathrm{Y}$ \\
\hline 68 & 406 & 18.3 & $\mathrm{Y}$ & 2692 & 528 & $\mathrm{Y}$ & $\mathrm{Y}$ \\
\hline 69 & 356 & 16.8 & $\mathrm{Y}$ & 1214 & 434 & $\mathrm{Y}$ & $\mathrm{Y}$ \\
\hline 70 & 356 & 21.3 & $\mathrm{Y}$ & 2089 & 316 & $\mathrm{Y}$ & $\mathrm{Y}$ \\
\hline 71 & 406 & 21.3 & $\mathrm{Y}$ & 2128 & 385 & $\mathrm{Y}$ & $\mathrm{Y}$ \\
\hline 72 & 356 & 15.8 & $\mathrm{~N}$ & 655 & 1208 & $\mathrm{Y}$ & $\mathrm{N}$ \\
\hline 73 & 406 & 21.3 & $\mathrm{~N}$ & 943 & 1732 & $\mathrm{Y}$ & $\mathrm{N}$ \\
\hline 74 & 406 & 19.8 & $\mathrm{~N}$ & 1201 & 1718 & $\mathrm{Y}$ & $\mathrm{N}$ \\
\hline 75 & 356 & 13.7 & $\mathrm{~N}$ & 794 & 1108 & $\mathrm{~N}$ & $\mathrm{~N}$ \\
\hline 76 & 406 & 21.8 & $\mathrm{~N}$ & 1112 & 1482 & $\mathrm{~N}$ & $\mathrm{~N}$ \\
\hline 77 & 406 & 21.8 & $\mathrm{~N}$ & 1334 & 2288 & $\mathrm{~N}$ & $\mathrm{~N}$ \\
\hline 78 & 406 & 21.8 & $\mathrm{~N}$ & 1334 & 1913 & $\mathrm{~N}$ & $\mathrm{~N}$ \\
\hline 79 & 356 & 5.6 & $\mathrm{~N}$ & 714 & 1071 & $\mathrm{Y}$ & $\mathrm{N}$ \\
\hline 80 & 356 & 6.6 & $\mathrm{~N}$ & 611 & 1484 & $\mathrm{~N}$ & $\mathrm{~N}$ \\
\hline 81 & 457 & 9.4 & $\mathrm{~N}$ & 442 & 1015 & $\mathrm{Y}$ & $\mathrm{N}$ \\
\hline 82 & 406 & 15.2 & $\mathrm{~N}$ & 1090 & 1030 & $\mathrm{Y}$ & $\mathrm{N}$ \\
\hline 83 & 406 & 15.2 & $\mathrm{~N}$ & 900 & 1599 & $\mathrm{~N}$ & $\mathrm{~N}$ \\
\hline 84 & 356 & 15.2 & $\mathrm{~N}$ & 720 & 1171 & $\mathrm{Y}$ & $\mathrm{N}$ \\
\hline 85 & 406 & 24.4 & $\mathrm{~N}$ & 1088 & 1812 & $\mathrm{Y}$ & $\mathrm{N}$ \\
\hline 86 & 406 & 24.4 & $\mathrm{~N}$ & 741 & 2006 & $\mathrm{Y}$ & $\mathrm{N}$ \\
\hline 87 & 406 & 24.4 & $\mathrm{~N}$ & 875 & 1936 & $\mathrm{Y}$ & $\mathrm{N}$ \\
\hline 88 & 406 & 15.8 & $\mathrm{~N}$ & 1150 & 473 & $\mathrm{~N}$ & $\mathrm{~N}$ \\
\hline 89 & 406 & 21.0 & $\mathrm{~N}$ & 1112 & 1345 & $\mathrm{~N}$ & $\mathrm{~N}$ \\
\hline 90 & 406 & 21.0 & $\mathrm{~N}$ & 1334 & 1996 & $\mathrm{~N}$ & $\mathrm{~N}$ \\
\hline 91 & 406 & 21.0 & $\mathrm{~N}$ & 1134 & 1756 & $\mathrm{~N}$ & $\mathrm{~N}$ \\
\hline 92 & 356 & 12.2 & $\mathrm{~N}$ & 970 & 1736 & $\mathrm{~N}$ & $\mathrm{~N}$ \\
\hline 93 & 356 & 16.8 & $\mathrm{~N}$ & 1423 & 2238 & $\mathrm{~N}$ & $\mathrm{~N}$ \\
\hline 94 & 356 & 15.2 & $\mathrm{~N}$ & 1423 & 2120 & $\mathrm{~N}$ & $\mathrm{~N}$ \\
\hline 95 & 356 & 24.4 & $\mathrm{~N}$ & 2180 & 3147 & $\mathrm{~N}$ & $\mathrm{~N}$ \\
\hline 96 & 356 & 16.8 & $\mathrm{~N}$ & 1423 & 3068 & $\mathrm{~N}$ & $\mathrm{~N}$ \\
\hline 97 & 800 & 24.0 & $\mathrm{Y}$ & 2687 & 1502 & $\mathrm{Y}$ & $\mathrm{N}$ \\
\hline 98 & 600 & 22.5 & $\mathrm{Y}$ & 1612 & 1637 & $\mathrm{Y}$ & $\mathrm{N}$ \\
\hline 99 & 800 & 24.1 & $\mathrm{Y}$ & 4286 & 3040 & $\mathrm{~N}$ & $\mathrm{~N}$ \\
\hline 100 & 456 & 9.1 & $\mathrm{Y}$ & 1156 & 338 & $\mathrm{Y}$ & $\mathrm{N}$ \\
\hline 101 & 457 & 22.9 & $\mathrm{~N}$ & 1050 & 2060 & $\mathrm{Y}$ & $\mathrm{N}$ \\
\hline 102 & 406 & 14.9 & $\mathrm{Y}$ & 1096 & 696 & $\mathrm{Y}$ & $\mathrm{Y}$ \\
\hline 103 & 406 & 18.0 & $\mathrm{~N}$ & 1188 & 1034 & $\mathrm{Y}$ & $\mathrm{N}$ \\
\hline 104 & 406 & 12.2 & $\mathrm{~N}$ & 1205 & 1186 & $\mathrm{~N}$ & $\mathrm{~N}$ \\
\hline
\end{tabular}




\begin{tabular}{|c|c|c|c|c|c|c|c|}
\hline 105 & 356 & 14.6 & $\mathrm{~N}$ & 731 & 1187 & $\mathrm{Y}$ & $\mathrm{N}$ \\
\hline 106 & 406 & 27.4 & $\mathrm{Y}$ & 2433 & 2664 & $\mathrm{Y}$ & $\mathrm{N}$ \\
\hline 107 & 406 & 27.4 & $\mathrm{Y}$ & 2979 & 2448 & $\mathrm{Y}$ & $\mathrm{N}$ \\
\hline 108 & 406 & 19.8 & $\mathrm{~N}$ & 3608 & 3185 & $\mathrm{~N}$ & $\mathrm{~N}$ \\
\hline 109 & 406 & 14.6 & $\mathrm{Y}$ & 2404 & 1363 & $\mathrm{Y}$ & $\mathrm{N}$ \\
\hline 110 & 406 & 10.7 & $\mathrm{~N}$ & 3257 & 296 & $\mathrm{~N}$ & $\mathrm{~N}$ \\
\hline 111 & 406 & 24.8 & $\mathrm{Y}$ & 2260 & 1611 & $\mathrm{Y}$ & $\mathrm{N}$ \\
\hline 112 & 406 & 23.9 & $\mathrm{Y}$ & 2037 & 1466 & $\mathrm{Y}$ & $\mathrm{N}$ \\
\hline 66 & 406 & 22.4 & $\mathrm{Y}$ & 3040 & 450 & $\mathrm{Y}$ & Y \\
\hline 67 & 406 & 19.8 & $\mathrm{Y}$ & 834 & 520 & $\mathrm{Y}$ & $\mathrm{Y}$ \\
\hline 68 & 406 & 18.3 & $\mathrm{Y}$ & 2692 & 528 & $\mathrm{Y}$ & $\mathrm{Y}$ \\
\hline 69 & 356 & 16.8 & $\mathrm{Y}$ & 1214 & 434 & $\mathrm{Y}$ & $\mathrm{Y}$ \\
\hline 70 & 356 & 21.3 & $\mathrm{Y}$ & 2089 & 316 & $\mathrm{Y}$ & $\mathrm{Y}$ \\
\hline 71 & 406 & 21.3 & $\mathrm{Y}$ & 2128 & 385 & $\mathrm{Y}$ & Y \\
\hline 72 & 356 & 15.8 & $\mathrm{~N}$ & 655 & 1208 & $\mathrm{Y}$ & $\mathrm{N}$ \\
\hline 73 & 406 & 21.3 & $\mathrm{~N}$ & 943 & 1732 & $\mathrm{Y}$ & $\mathrm{N}$ \\
\hline 74 & 406 & 19.8 & $\mathrm{~N}$ & 1201 & 1718 & $\mathrm{Y}$ & $\mathrm{N}$ \\
\hline 75 & 356 & 13.7 & $\mathrm{~N}$ & 794 & 1108 & $\mathrm{~N}$ & $\mathrm{~N}$ \\
\hline 76 & 406 & 21.8 & $\mathrm{~N}$ & 1112 & 1482 & $\mathrm{~N}$ & $\mathrm{~N}$ \\
\hline 77 & 406 & 21.8 & $\mathrm{~N}$ & 1334 & 2288 & $\mathrm{~N}$ & $\mathrm{~N}$ \\
\hline 78 & 406 & 21.8 & $\mathrm{~N}$ & 1334 & 1913 & $\mathrm{~N}$ & $\mathrm{~N}$ \\
\hline 79 & 356 & 5.6 & $\mathrm{~N}$ & 714 & 1071 & $\mathrm{Y}$ & $\mathrm{N}$ \\
\hline 80 & 356 & 6.6 & $\mathrm{~N}$ & 611 & 1484 & $\mathrm{~N}$ & $\mathrm{~N}$ \\
\hline 81 & 457 & 9.4 & $\mathrm{~N}$ & 442 & 1015 & $\mathrm{Y}$ & $\mathrm{N}$ \\
\hline 82 & 406 & 15.2 & $\mathrm{~N}$ & 1090 & 1030 & $\mathrm{Y}$ & $\mathrm{N}$ \\
\hline 83 & 406 & 15.2 & $\mathrm{~N}$ & 900 & 1599 & $\mathrm{~N}$ & $\mathrm{~N}$ \\
\hline 84 & 356 & 15.2 & $\mathrm{~N}$ & 720 & 1171 & $\mathrm{Y}$ & $\mathrm{N}$ \\
\hline 85 & 406 & 24.4 & $\mathrm{~N}$ & 1088 & 1812 & $\mathrm{Y}$ & $\mathrm{N}$ \\
\hline 86 & 406 & 24.4 & $\mathrm{~N}$ & 741 & 2006 & $\mathrm{Y}$ & $\mathrm{N}$ \\
\hline 87 & 406 & 24.4 & $\mathrm{~N}$ & 875 & 1936 & $\mathrm{Y}$ & $\mathrm{N}$ \\
\hline 88 & 406 & 15.8 & $\mathrm{~N}$ & 1150 & 473 & $\mathrm{~N}$ & $\mathrm{~N}$ \\
\hline 89 & 406 & 21.0 & $\mathrm{~N}$ & 1112 & 1345 & $\mathrm{~N}$ & $\mathrm{~N}$ \\
\hline 90 & 406 & 21.0 & $\mathrm{~N}$ & 1334 & 1996 & $\mathrm{~N}$ & $\mathrm{~N}$ \\
\hline 91 & 406 & 21.0 & $\mathrm{~N}$ & 1134 & 1756 & $\mathrm{~N}$ & $\mathrm{~N}$ \\
\hline 92 & 356 & 12.2 & $\mathrm{~N}$ & 970 & 1736 & $\mathrm{~N}$ & $\mathrm{~N}$ \\
\hline 93 & 356 & 16.8 & $\mathrm{~N}$ & 1423 & 2238 & $\mathrm{~N}$ & $\mathrm{~N}$ \\
\hline 94 & 356 & 15.2 & $\mathrm{~N}$ & 1423 & 2120 & $\mathrm{~N}$ & $\mathrm{~N}$ \\
\hline 95 & 356 & 24.4 & $\mathrm{~N}$ & 2180 & 3147 & $\mathrm{~N}$ & $\mathrm{~N}$ \\
\hline 96 & 356 & 16.8 & $\mathrm{~N}$ & 1423 & 3068 & $\mathrm{~N}$ & $\mathrm{~N}$ \\
\hline
\end{tabular}




\begin{tabular}{ccccccccc}
97 & 800 & 24.0 & $\mathrm{Y}$ & 2687 & 1502 & $\mathrm{Y}$ & $\mathrm{N}$ & 5 \\
98 & 600 & 22.5 & $\mathrm{Y}$ & 1612 & 1637 & $\mathrm{Y}$ & $\mathrm{N}$ & 5 \\
99 & 800 & 24.1 & $\mathrm{Y}$ & 4286 & 3040 & $\mathrm{~N}$ & $\mathrm{~N}$ & 5 \\
100 & 456 & 9.1 & $\mathrm{Y}$ & 1156 & 338 & $\mathrm{Y}$ & $\mathrm{N}$ & 6 \\
101 & 457 & 22.9 & $\mathrm{~N}$ & 1050 & 2060 & $\mathrm{Y}$ & $\mathrm{N}$ & 7 \\
102 & 406 & 14.9 & $\mathrm{Y}$ & 1096 & 696 & $\mathrm{Y}$ & $\mathrm{Y}$ & 7 \\
103 & 406 & 18.0 & $\mathrm{~N}$ & 1188 & 1034 & $\mathrm{Y}$ & $\mathrm{N}$ & 7 \\
104 & 406 & 12.2 & $\mathrm{~N}$ & 1205 & 1186 & $\mathrm{~N}$ & $\mathrm{~N}$ & 7 \\
105 & 356 & 14.6 & $\mathrm{~N}$ & 731 & 1187 & $\mathrm{Y}$ & $\mathrm{N}$ & 7 \\
106 & 406 & 27.4 & $\mathrm{Y}$ & 2433 & 2664 & $\mathrm{Y}$ & $\mathrm{N}$ & 7 \\
107 & 406 & 27.4 & $\mathrm{Y}$ & 2979 & 2448 & $\mathrm{Y}$ & $\mathrm{N}$ & 7 \\
108 & 406 & 19.8 & $\mathrm{~N}$ & 3608 & 3185 & $\mathrm{~N}$ & $\mathrm{~N}$ & 7 \\
109 & 406 & 14.6 & $\mathrm{Y}$ & 2404 & 1363 & $\mathrm{Y}$ & $\mathrm{N}$ & 7 \\
110 & 406 & 10.7 & $\mathrm{~N}$ & 3257 & 296 & $\mathrm{~N}$ & $\mathrm{~N}$ & 7 \\
111 & 406 & 24.8 & $\mathrm{Y}$ & 2260 & 1611 & $\mathrm{Y}$ & $\mathrm{N}$ & 7 \\
112 & 406 & 23.9 & $\mathrm{Y}$ & 2037 & 1466 & $\mathrm{Y}$ & $\mathrm{N}$ & 7 \\
\hline
\end{tabular}

